\title{
Triplet Distribution in a Symmetrical Zinc(II) Porphyrin- BODIPY Pentameric Array
}

Özgür Altan Bozdemir, ${ }^{\star a, b}$ Demet Demirci Gultekin ${ }^{c}$ and Anthony Harriman ${ }^{\star a}$

(a) Molecular Photonics Laboratory, SNES-Chemistry, Bedson Building, Newcastle University, Newcastle upon Tyne, NE1 7RU, UK. (b) Department of Chemistry, Ataturk University, Erzurum, 25240, Turkey. (c) Askale Vocational Collage, Department of Metallurgical Program, Ataturk University, 25500, Erzurum, Turkey.

\section{SUPPORTING INFORMATION}

TOTAL NUMBER OF PAGES: 43

List of Contents:

S1. Experimental details: Materials $\quad$ S2

S2. Overlap integrals and calculated rate constants for EET $\quad$ S17

S3. Sensitization of BOD triplet state S20

S4. Studies with $\mathrm{FbPB}_{4} \quad \mathrm{~S} 26$

S5. Determination of the fluorescence quantum yield for weak signals $\quad$ S31

S6. Additional spectroscopic information S33

S7. Triplet-triplet annihilation $\quad$ S38

S8. References $\quad$ S42 


\section{S1. Experimental details: Materials}

\section{S1.1 General Methods}

The four-fold Suzuki coupling for the synthesis of $\mathrm{ZnPB}_{4}$ was carried out following a reported procedure. ${ }^{S 1}$ All chemicals and solvents were purchased from Sigma-Aldrich and used without further purification. Reactions were monitored by thin layer chromatography using Merck TLC Silica gel $60 \mathrm{~F}_{254}$ and the plates were inspected by $254 \mathrm{~nm}$ or $365 \mathrm{~nm}$ UV-light. Column chromatography was performed over Merck Silica gel 60F (70-230 mesh ASTM). The ${ }^{1} \mathrm{H}$ - and ${ }^{13} \mathrm{C}$-NMR spectra were recorded on a Varian-400 or a Bruker-400 spectrometer in $\mathrm{CDCl}_{3}$ using tetramethylsilane as the internal reference. All spectra were recorded at $25^{\circ} \mathrm{C}$ and coupling constants ( $J$ values) are given in $\mathrm{Hz}$. Chemical shifts are given in parts per million (ppm). Abbreviations used to define multiplicities are as follows: $\mathrm{s}=$ singlet; $\mathrm{d}=$ doublet; $\mathrm{t}=$ triplet; $\mathrm{q}=$ quartet; $\mathrm{m}=$ multiplet; $\mathrm{br}=$ broad. Mass spectra were recorded on a Bruker microflex LT MALDI-TOF MS.

\section{S1.2. Synthesis}

Synthesis of 8-chlorophenyl-BODIPY (1)

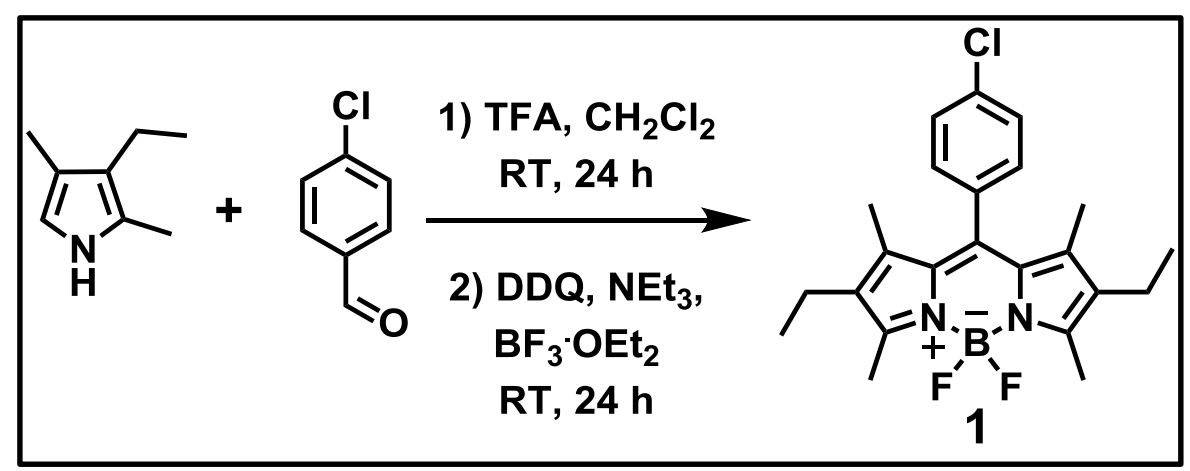

3-Ethyl-2,4-dimethyl-1H-pyrrole $(2.16 \mathrm{~mL}, 16 \mathrm{mmol})$ and 4-chlorobenzaldehyde $(1.124$ $\mathrm{g}, 8 \mathrm{mmol}$ ) were added to a $1 \mathrm{~L}$ round-bottomed flask and dissolved in dry $\mathrm{CH}_{2} \mathrm{Cl}_{2}(600$ $\mathrm{mL}$ ). TFA (10 drops) was added and the mixture was stirred at room temperature for $24 \mathrm{~h}$. DDQ (1.82 g, $8 \mathrm{mmol}$ ) was added in a single portion, and the reaction was stirred at room temperature overnight. $N, N$-Diisopropylethylamine $(16 \mathrm{~mL}, 91 \mathrm{mmol})$ and $\mathrm{BF}_{3} \cdot \mathrm{Et}_{2} \mathrm{O}(17 \mathrm{~mL}, 128 \mathrm{mmol})$ were added and the mixture was stirred at room temperature for $24 \mathrm{~h}$. Then, washed with water $(3 \times 150 \mathrm{~mL})$ and brine $(3 \times 150 \mathrm{~mL})$. The combined organic layers were dried over $\mathrm{Na}_{2} \mathrm{SO}_{4}$ and concentrated in vacuo. The residue was purified by column chromatography $\left(\mathrm{SiO}_{2}, \mathrm{CH}_{2} \mathrm{Cl}_{2}\right)$ to afford 1 as a dark- 
violet solid (1.82 g, 55\%). ${ }^{1} \mathrm{H}$ NMR (400 MHz, $\left.\mathrm{CDCl}_{3}\right) \delta \mathrm{ppm:} 7.51$ (d, $J=8.5 \mathrm{~Hz}, 2 \mathrm{H}$ ), $7.26(\mathrm{~d}, J=8.5 \mathrm{~Hz}, 2 \mathrm{H}), 2.56(\mathrm{~s}, 6 \mathrm{H}), 2.35$ (q, J = 7.6 Hz, 4H), $1.34(\mathrm{~s}, 6 \mathrm{H}), 1.00$ (t, J $=7.5 \mathrm{~Hz}, 6 \mathrm{H}) \cdot{ }^{13} \mathrm{C} \mathrm{NMR}\left(\mathrm{CDCl}_{3}, 100 \mathrm{MHz}\right) \delta \mathrm{ppm}: 154.2,138.5,138.1,134.9,134.3$, 133.0, 130.6, 129.9, 129.4, 17.1, 14.6, 12.5, 11.9.

Synthesis of boronate ester-BODIPY

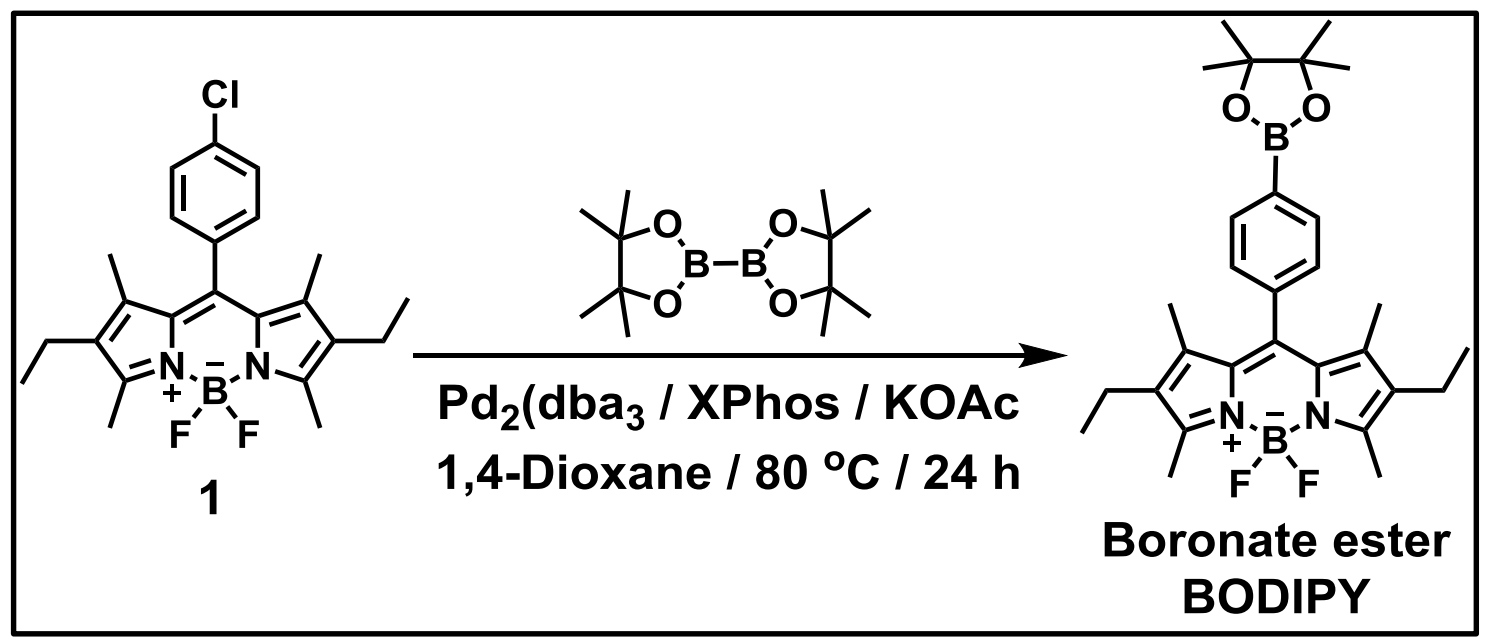

Aliquots of $1(0.10 \mathrm{~g}, 0.241 \mathrm{mmol})$, bis(pinacolato)diboron $(0.19 \mathrm{mg}, 0.75 \mathrm{mmol})$, $\mathrm{Pd}_{2}(\mathrm{dba})_{3}(2.3 \mathrm{mg}, 0.0025 \mathrm{mmol})$, XPhos ( $\left.4.8 \mathrm{mg}, 0.01 \mathrm{mmol}\right)$, and KOAc (75 mg, 0.75 $\mathrm{mmol}$ ) were added into an oven-dried $50 \mathrm{~mL}$ Schlenk tube. The Schlenk tube was capped with a rubber septum and then evacuated and backfilled with nitrogen three times. 1,4-Dioxane $(4 \mathrm{~mL})$ was added via syringe and the resulting mixture was deoxygenated by three freeze-thaw-pump cycles. The reaction mixture was heated to $110^{\circ} \mathrm{C}$ under a nitrogen atmosphere for $24 \mathrm{~h}$. Then, the reaction mixture was diluted with $\mathrm{CH}_{2} \mathrm{Cl}_{2}(50 \mathrm{~mL})$ and washed with brine $(3 \times 100 \mathrm{~mL})$. The organic layer was dried over $\mathrm{Na}_{2} \mathrm{SO}_{4}$, filtered and concentrated in vacuo. The residue was purified by column chromatography $\left(\mathrm{SiO}_{2}\right.$, petroleum ether $\left./ \mathrm{CH}_{2} \mathrm{Cl}_{2}, 50: 50\right)$ to afford Boronate ester BODIPY as an orange solid (90 mg, 74\%). ${ }^{1} \mathrm{H}$ NMR (300 MHz, $\left.\mathrm{CDCl}_{3}\right) \delta$ ppm: 7.82 (d, $J=7.8 \mathrm{~Hz}, 2 \mathrm{H}$ ), 7.22 (d, $J=7.2 \mathrm{~Hz}, 2 \mathrm{H}$ ), 2.45 (s, 6H), 2.24 (q, $J=7.5 \mathrm{~Hz}, 4 \mathrm{H}$ ), 1.32 (s, $12 \mathrm{H}), 1.19(\mathrm{~s}, 6 \mathrm{H}), 0.91(\mathrm{t}, J=7.5 \mathrm{~Hz}, 6 \mathrm{H}) .{ }^{13} \mathrm{C} \mathrm{NMR}\left(\mathrm{CDCl}_{3}, 100 \mathrm{MHz}\right) \delta \mathrm{ppm}: 152.6$, 139.0, 137.6, 137.3, 134.2, 131.6, 129.5, 126.5, 83.0, 28.6, 23.8, 16.0, 13.5, 11.4, 10.7. 
Synthesis of 5,10,15,20-tetrakis(4'-bromophenyl)porphyrin

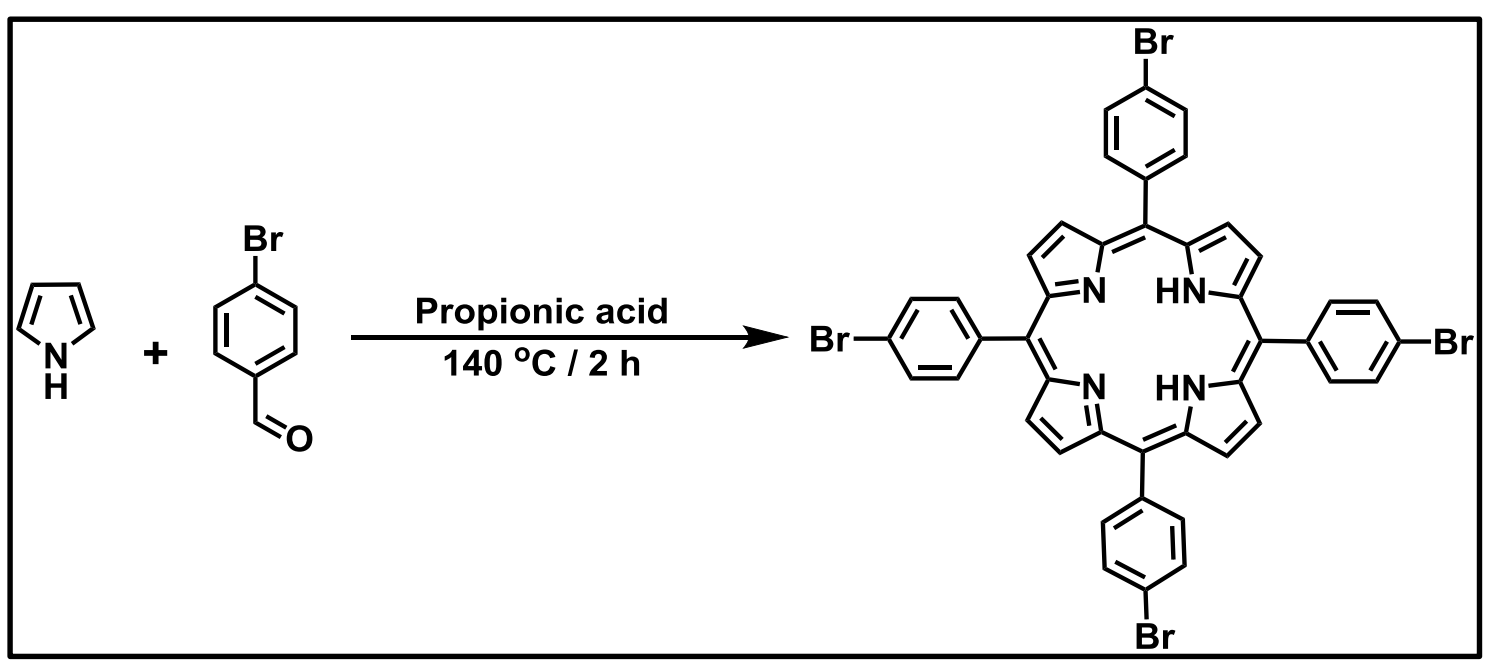

A solution of 4-bromobenzaldehyde $(3.7 \mathrm{~g}, 20 \mathrm{mmol})$ in propionic acid $(150 \mathrm{~mL})$ was refluxed at $140^{\circ} \mathrm{C}$. Pyrrole $(1.38 \mathrm{~mL}, 20 \mathrm{mmol})$ was added dropwise and the reaction mixture was stirred at $140^{\circ} \mathrm{C}$ for $2 \mathrm{~h}$. Reaction mixture was cooled to room temperature and the resulting dark violet precipitate was collected by filtration and washed with hot water then with methanol $(3 \times 50 \mathrm{~mL})$ The product was further purified by recrystallization from dichloromethane and methanol $(1.95 \mathrm{~g}, 33 \%) .{ }^{1} \mathrm{H} \mathrm{NMR}(300 \mathrm{MHz}$, $\left.\mathrm{CDCl}_{3}\right) \delta$ ppm: 8.86 (s, 8H, $\beta$-pyrrolic-H), 8.09 (d, $J=8.3 \mathrm{~Hz}, 8 \mathrm{H}$ ), $7.92(\mathrm{~d}, J=8.3 \mathrm{~Hz}$, $8 \mathrm{H}) .{ }^{13} \mathrm{C} \mathrm{NMR}\left(\mathrm{CDCl}_{3}, 75 \mathrm{MHz}\right) \delta \mathrm{ppm}: 140.8,135.8,130.0,122.6,121.0,119.0$.

Synthesis of Zinc(II)-tetra(4-bromophenyl)porphyrin

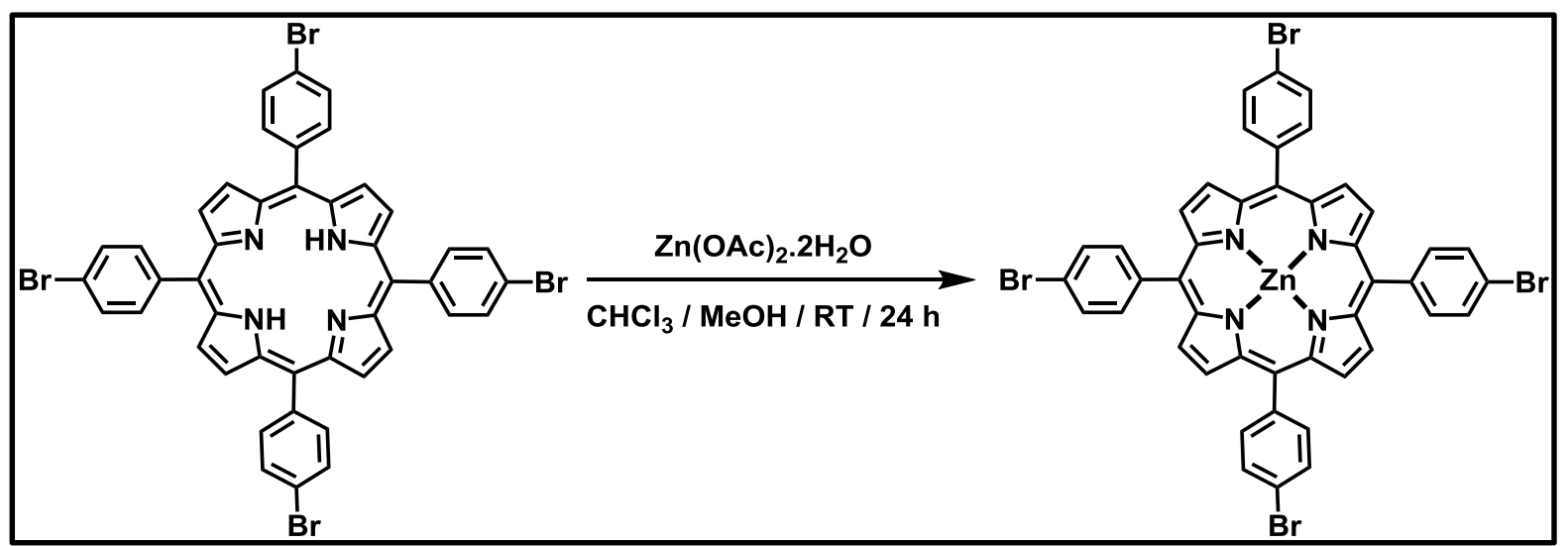

To a solution of 5,10,15,20-Tetrakis(4'-bromophenyl)porphyrin $(0,16 \mathrm{~g}, 0.16 \mathrm{mmol})$ in $\mathrm{CHCl}_{3}(100 \mathrm{~mL})$ was added $\mathrm{Zn}(\mathrm{OAc})_{2} .2 \mathrm{H}_{2} \mathrm{O}(53 \mathrm{mg}, 0.24 \mathrm{mmol})$ in $\mathrm{MeOH}(10 \mathrm{~mL})$ and the reaction mixture was stirred at room temperature in a nitrogen atmosphere for 24 h. After the completion of the reaction, the solvent was removed under reduced pressure and the residue was re-dissolved in $\mathrm{CH}_{2} \mathrm{Cl}_{2}$, followed by washing with water 
(3 $\times 100 \mathrm{~mL}$ ). The organic layer was dried over $\mathrm{Na}_{2} \mathrm{SO}_{4}$, filtered and concentrated in vacuo to afford Zinc-TetraBodıpyporphyrin as a dark-vıolet solid $(0,15 \mathrm{~g}, 98 \%) .{ }^{1} \mathrm{H}$ NMR (400 MHz, CDCl 3 ) $\delta$ ppm: 8.97 (s, 8H, $\beta$-pyrrolic-H), $8.10(\mathrm{~d}, J=8.3 \mathrm{~Hz}, 8 \mathrm{H}), 7.93$ (d, $J=8.3 \mathrm{~Hz}, 8 \mathrm{H}) .{ }^{13} \mathrm{C} \mathrm{NMR}\left(\mathrm{CDCl}_{3}, 100 \mathrm{MHz}\right) \delta \mathrm{ppm}: 150.0,135.7,135.0,132.1$, $129.8,119.9$.

Synthesis of $Z n P B_{4}$

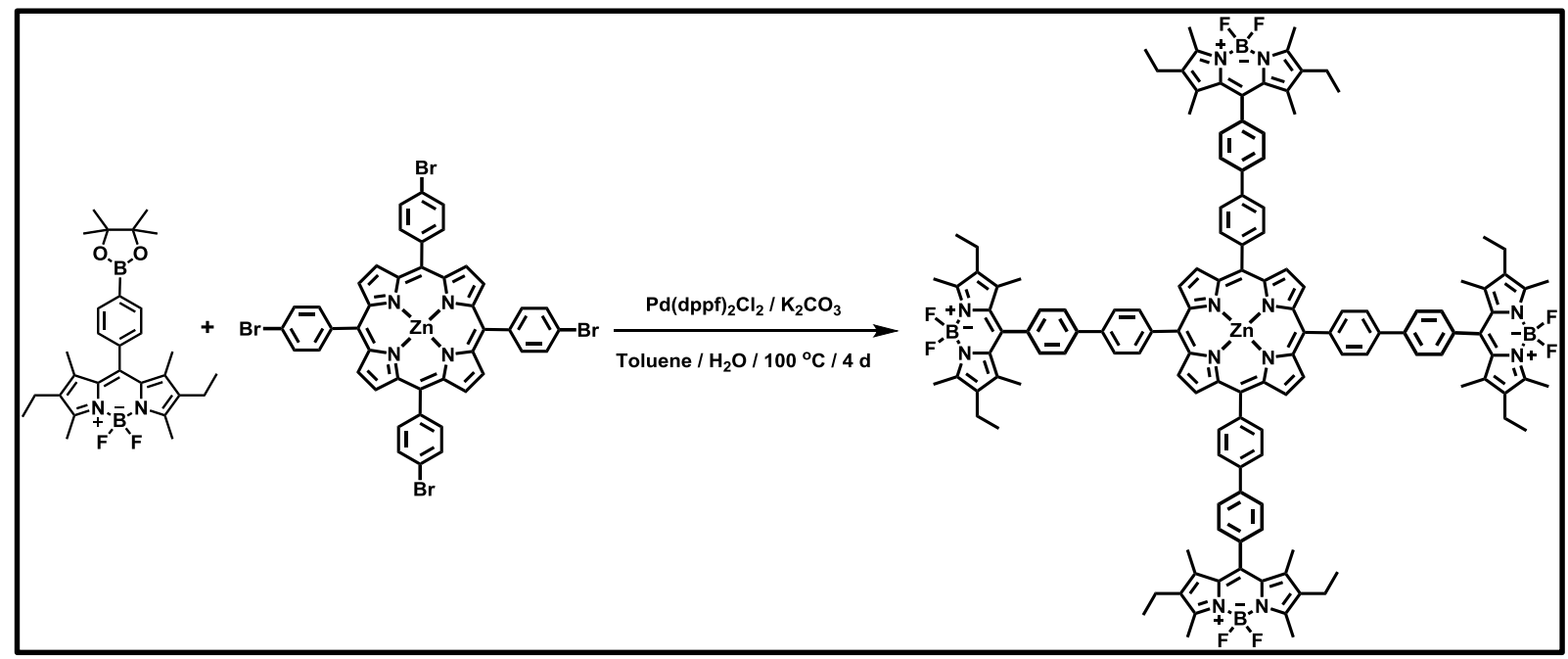

Boronate ester-BODIPY (80 mg, $0.16 \mathrm{mmol}$ ) Zinc-TetraBodipyporphyrin (20 mg, 0.02 $\mathrm{mmol}), \mathrm{K}_{2} \mathrm{CO}_{3}(0,22 \mathrm{~g}, 1.6 \mathrm{mmol})$ and $\mathrm{Pd}(\mathrm{dppf})_{2} \mathrm{Cl}_{2}(5 \mathrm{mg}, 0.007 \mathrm{mmol})$ were added into an oven-dried $10 \mathrm{~mL}$ Schlenk tube. The Schlenk tube was capped with a rubber septum and then evacuated and back- filled with nitrogen three times. Toluene $(6 \mathrm{~mL})$ and water $(1 \mathrm{~mL})$ were added via syringe and the resulting mixture was deoxygenated by three freeze-thaw-pump cycles. The reaction mixture was heated to $110^{\circ} \mathrm{C}$ under a nitrogen atmosphere for $18 \mathrm{~h}$. Then, the reaction mixture was diluted with $\mathrm{CH}_{2} \mathrm{Cl}_{2}$ (50 $\mathrm{mL})$ and washed with brine $(3 \times 100 \mathrm{~mL})$. The organic layer was dried over $\mathrm{Na}_{2} \mathrm{SO}_{4}$, filtered and concentrated in vacuo. The residue was purified by column chromatography ( $\mathrm{SiO}_{2}, \mathrm{CH}_{2} \mathrm{Cl}_{2}$ to $\mathrm{CH}_{2} \mathrm{Cl}_{2} / \mathrm{MeOH}$ 98:2) to afford $\mathrm{ZnPB}_{4}$ as a dark-violet solid (6.5 mg, 15\%). ${ }^{1} \mathrm{H}$ NMR (400 MHz, $\mathrm{CDCl}_{3}$ ) $\delta$ ppm: 9.03 (s, 8H), 8.32 (d, $J=7.2$ $\mathrm{Hz}, 8 \mathrm{H}), 8.10-8.02(\mathrm{~m}, 16 \mathrm{H}), 7.46(\mathrm{~d}, J=7.6 \mathrm{~Hz}, 8 \mathrm{H}), 2.51(\mathrm{~s}, 24 \mathrm{H}), 2.35-2.24(\mathrm{~m}$,

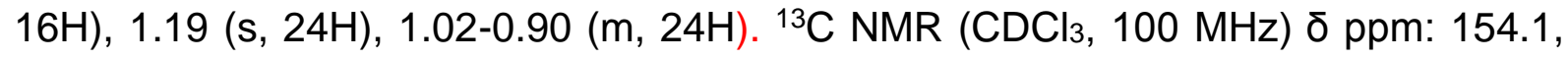
150.4, 142.6, 141.2, 140.0, 139.3, 138.6, 135.4, 135.3, 133.1, 132.3, 131.0, 129.9, 129.3, 127.9, 125.4, 121.0, 29.9, 17.3, 14.9, 12.2, Maldi-Tof Mass: m/z Calcd for [M+H $\left.\mathrm{H}_{2} \mathrm{O}\right]: 2192.986$; found: 2191.293. 
SG

S1.3. ${ }^{1} \mathrm{H}$ NMR, ${ }^{13} \mathrm{C}$ NMR, and Mass Spectra

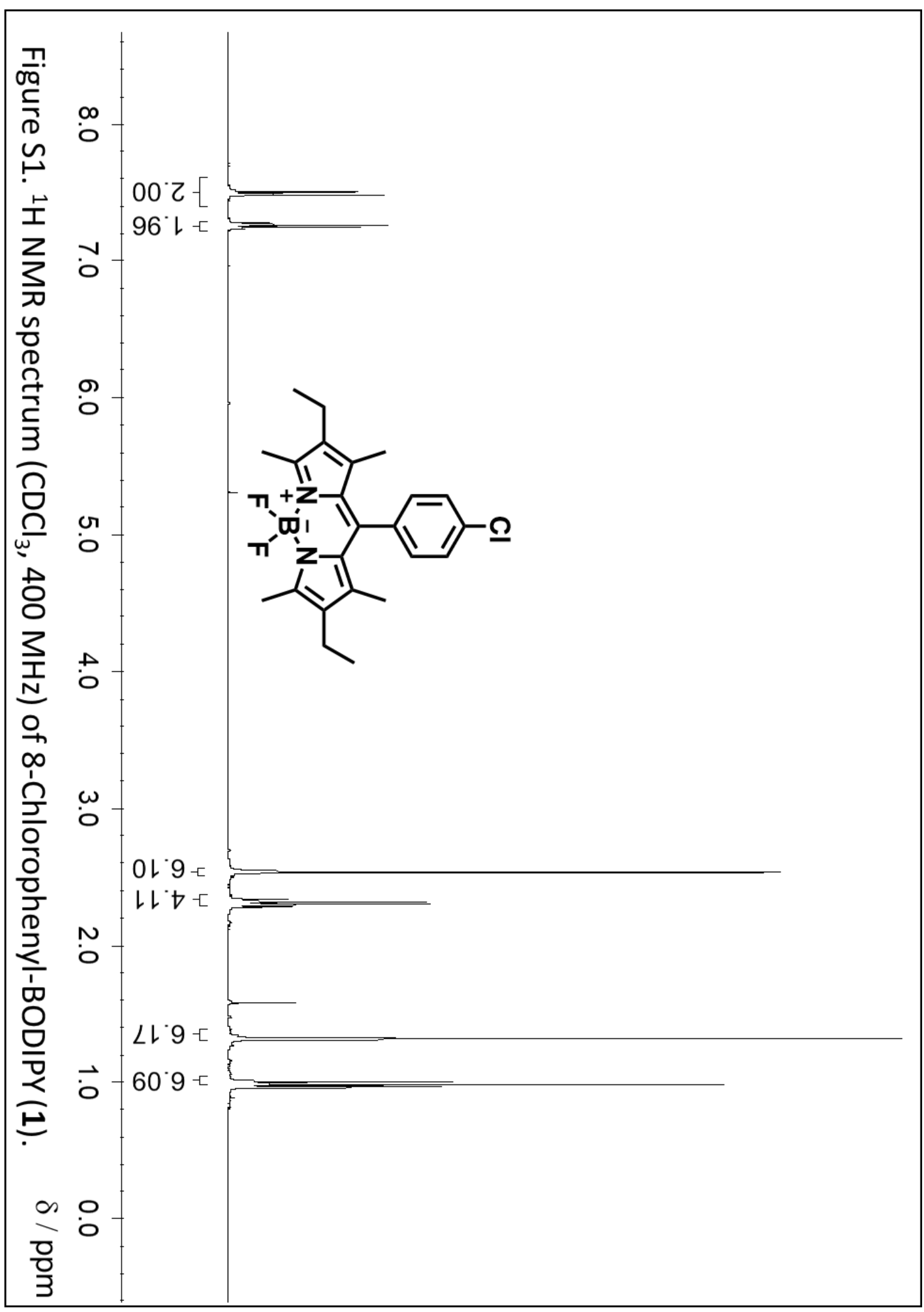


S7

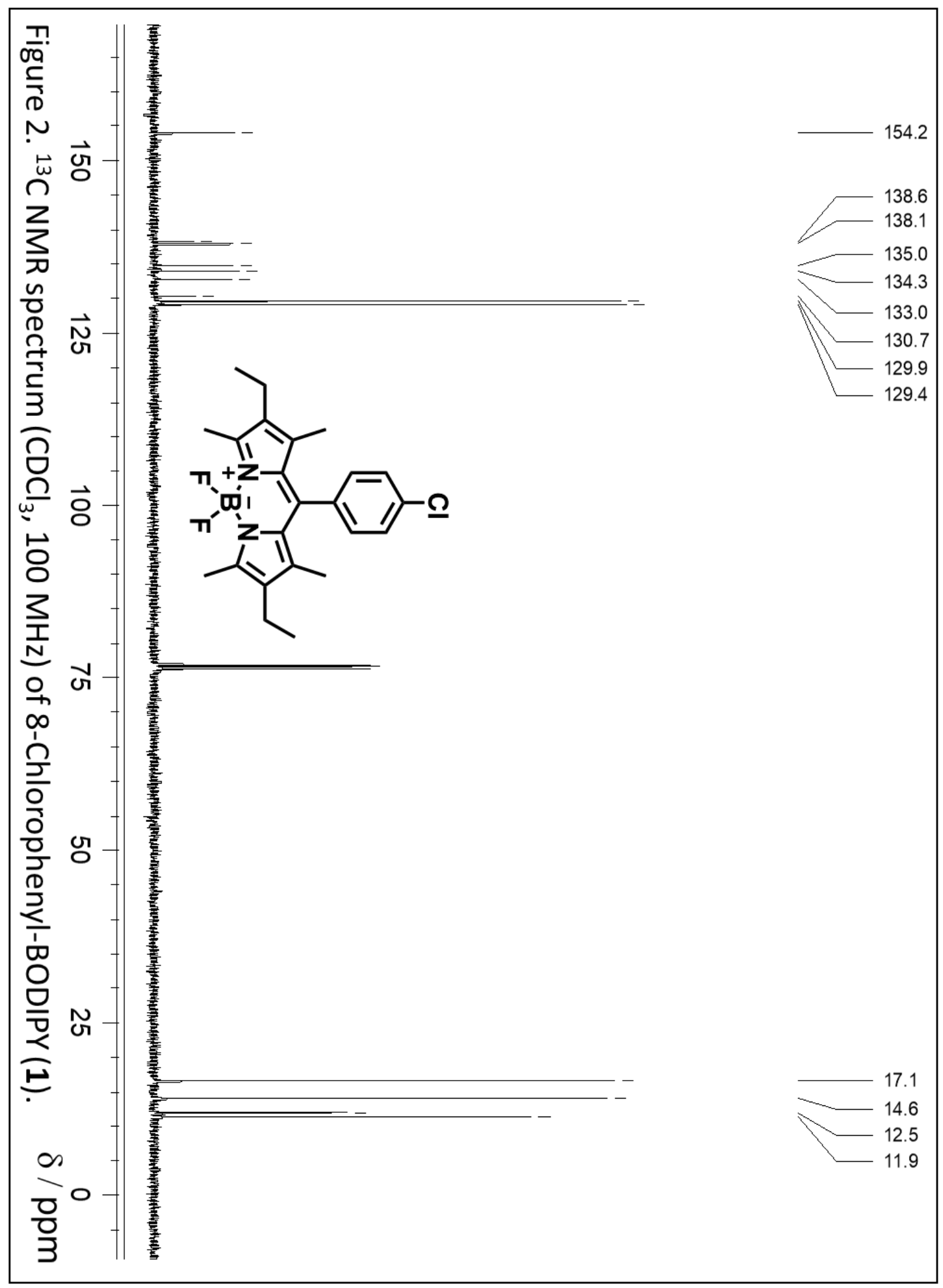




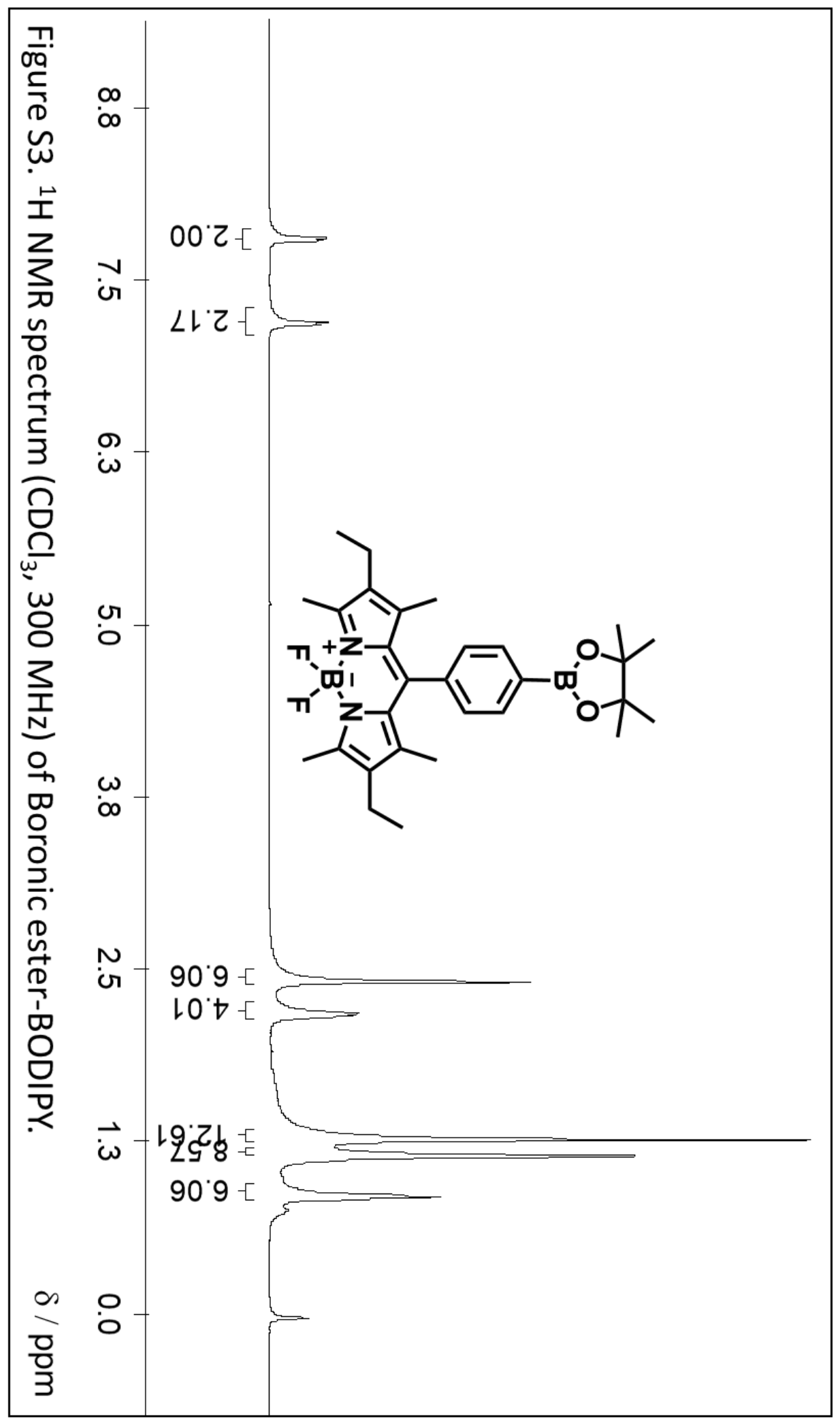




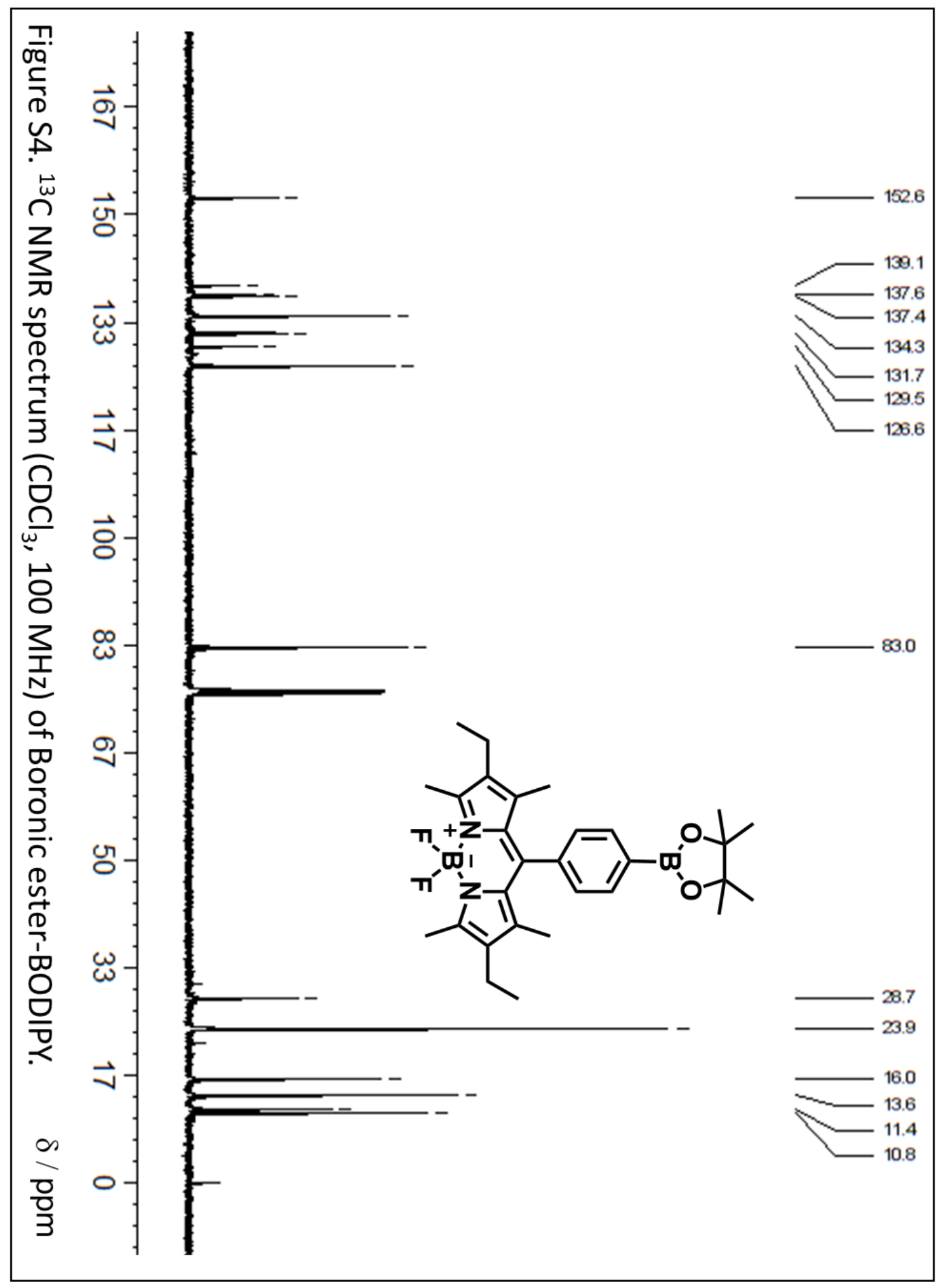




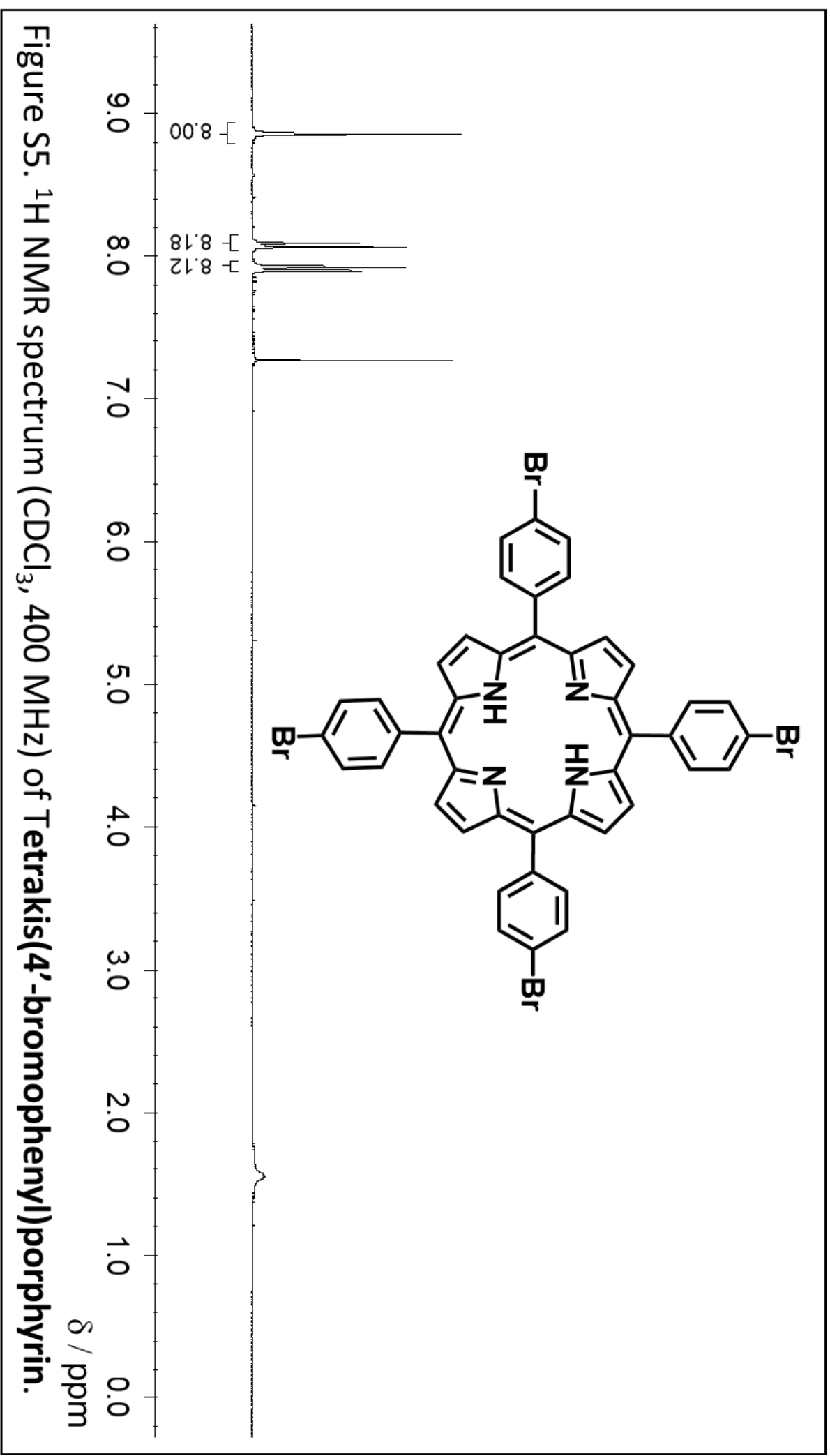




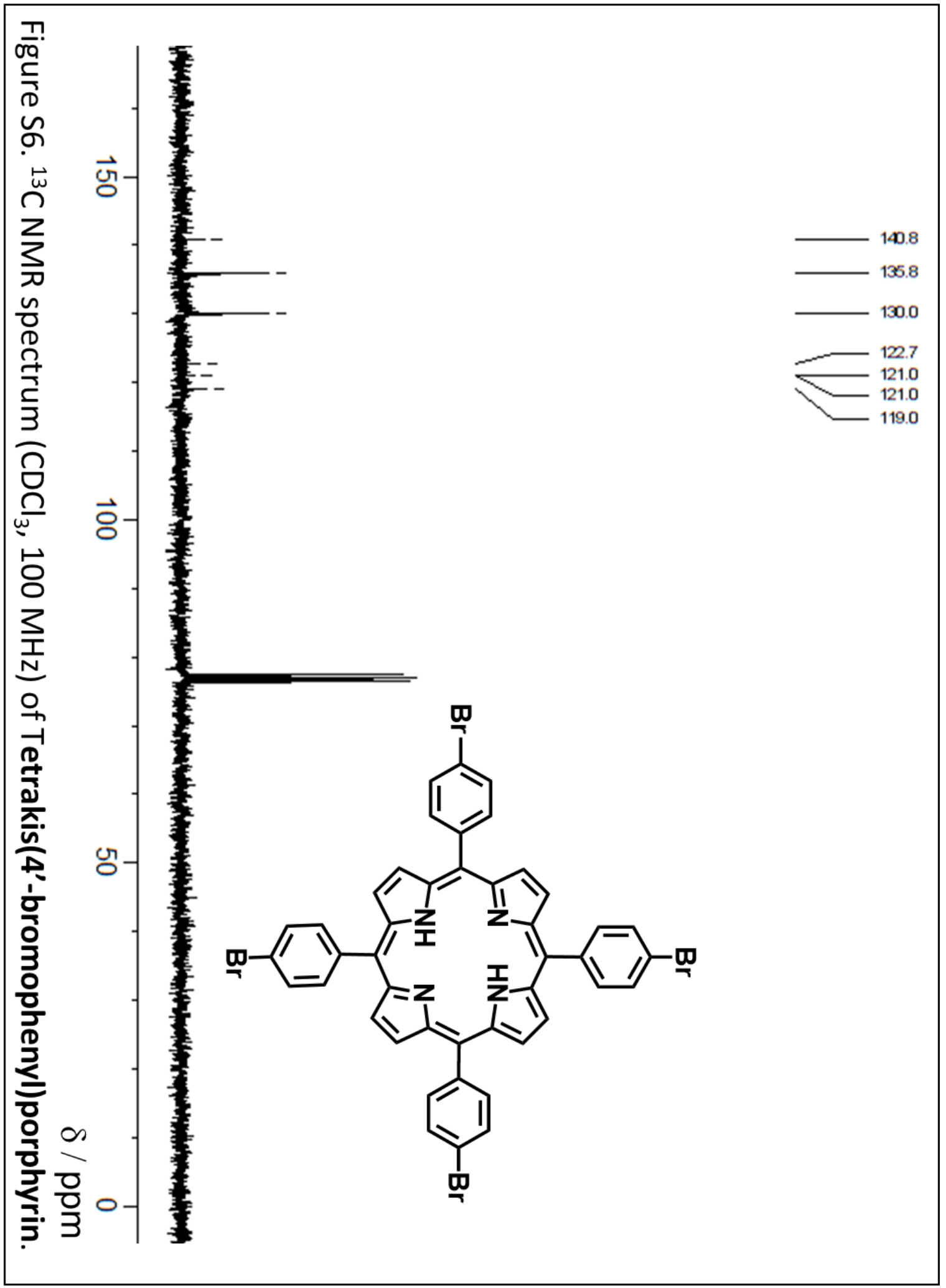




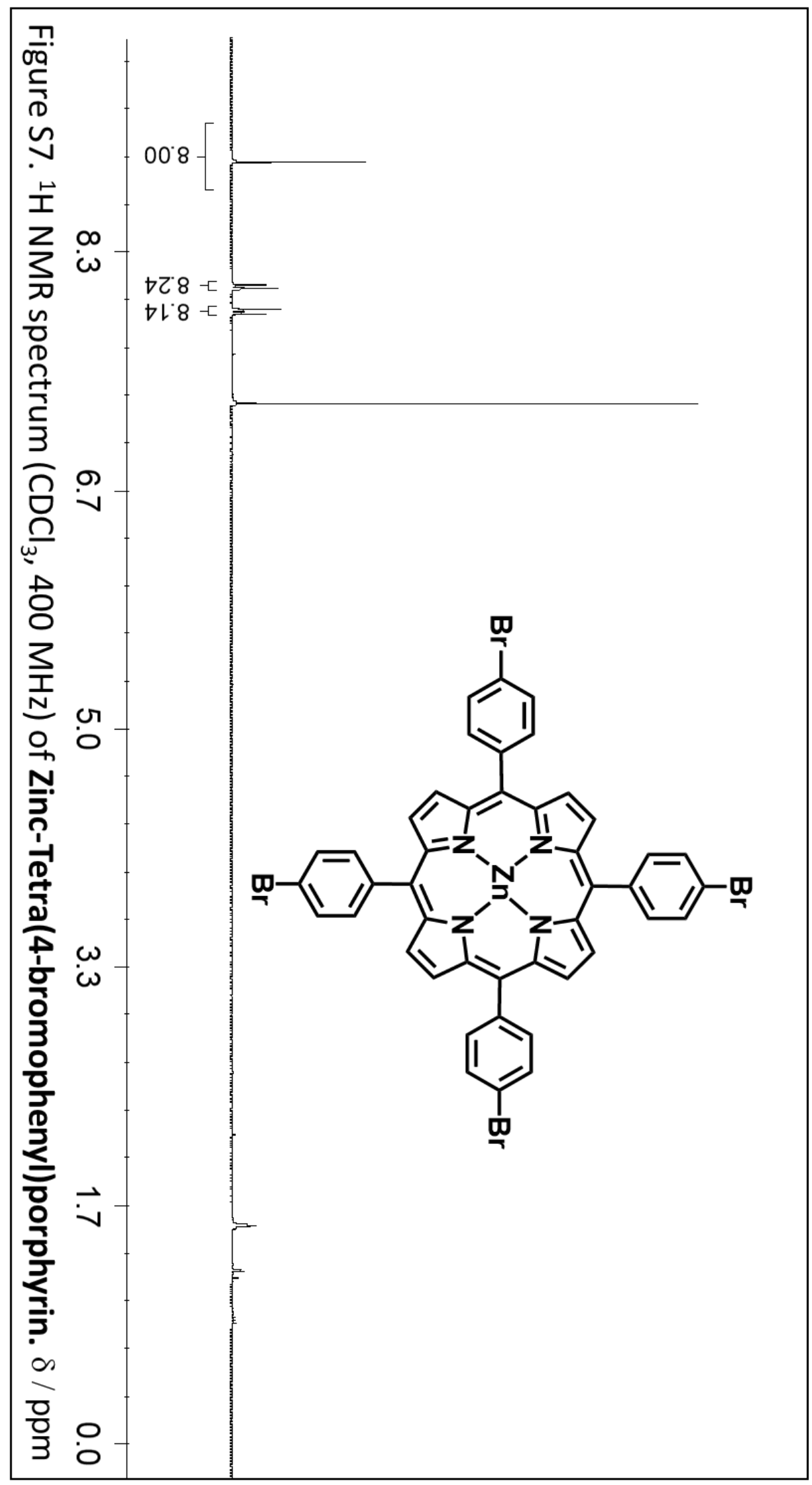




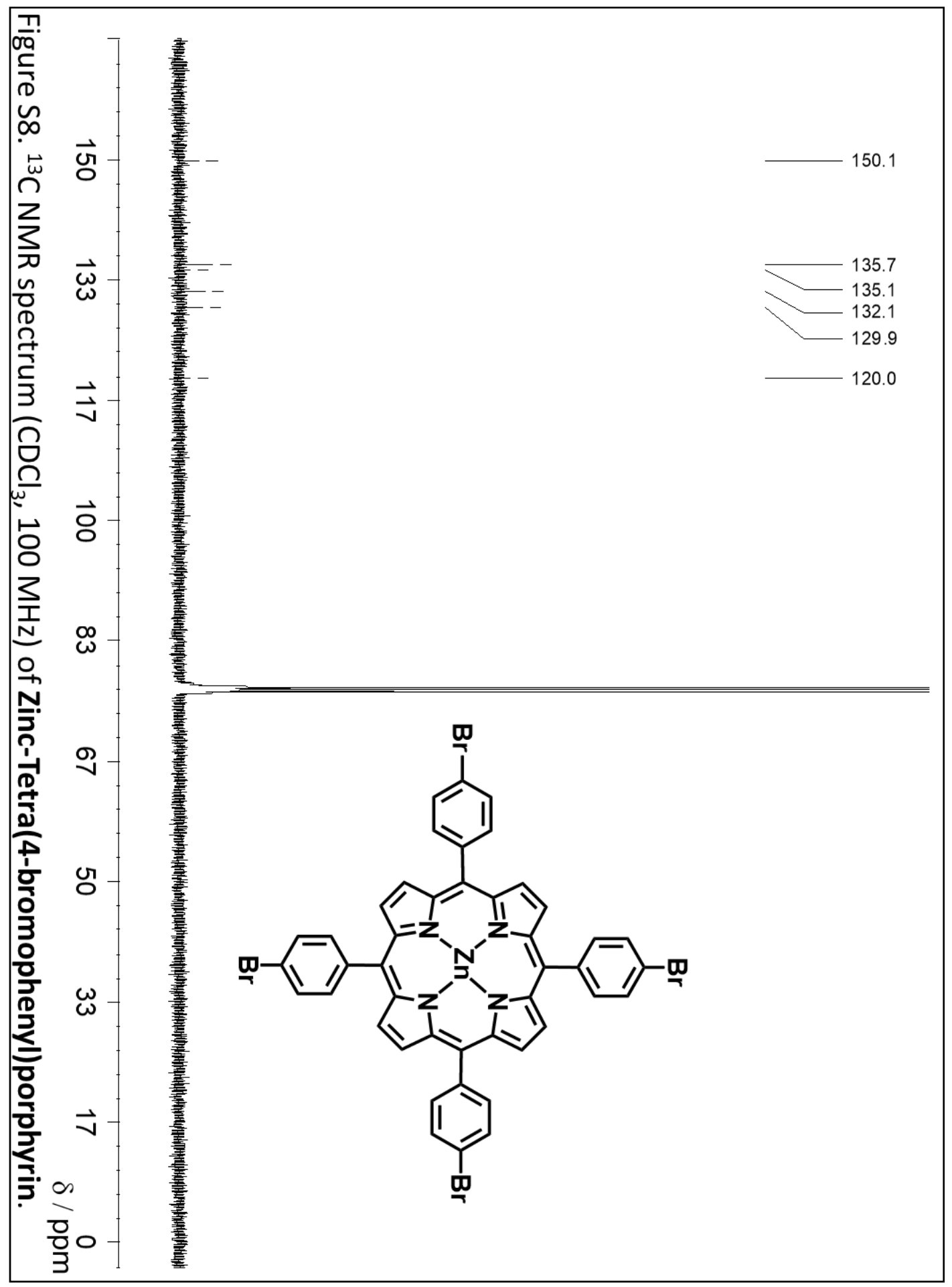




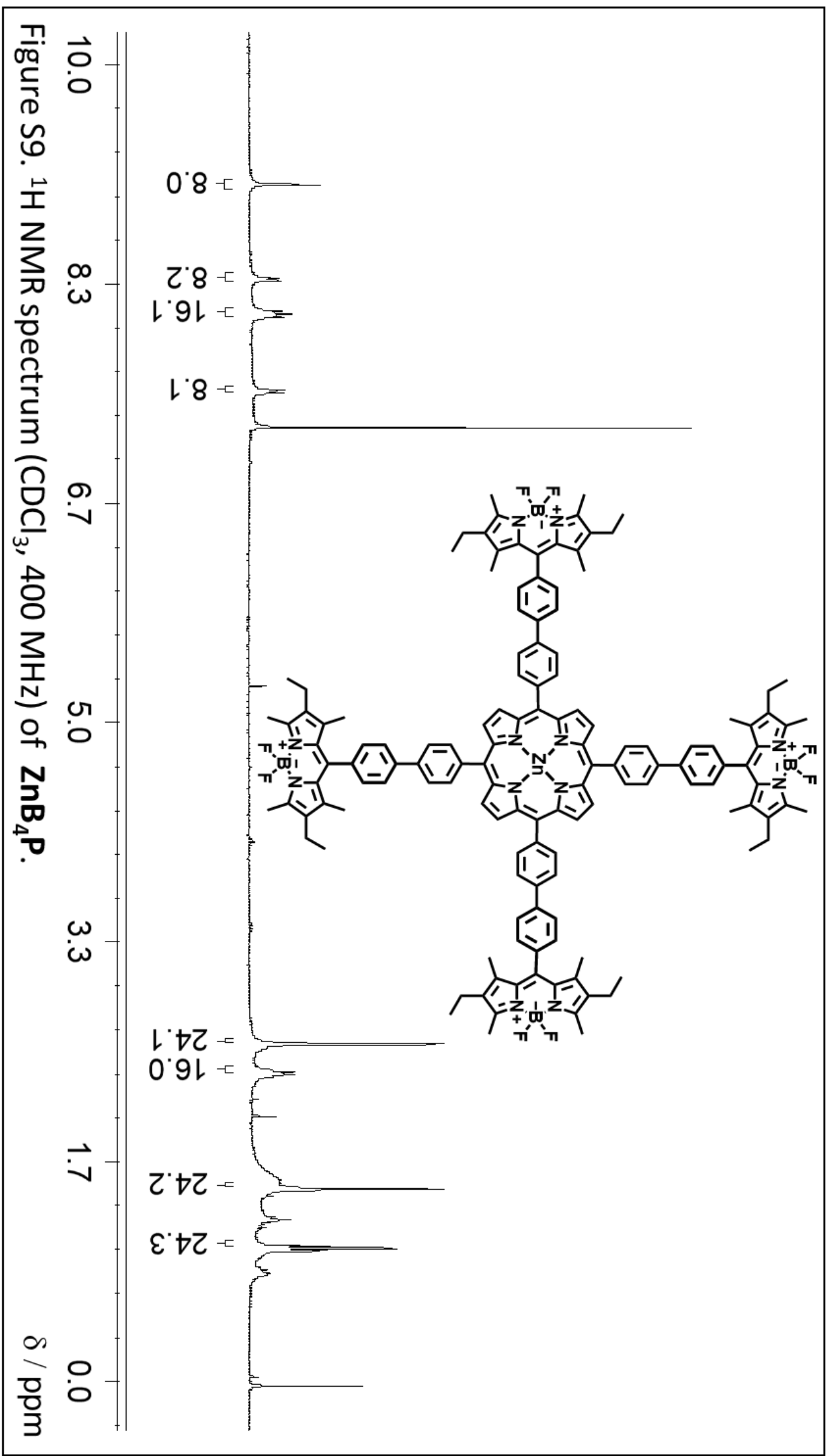




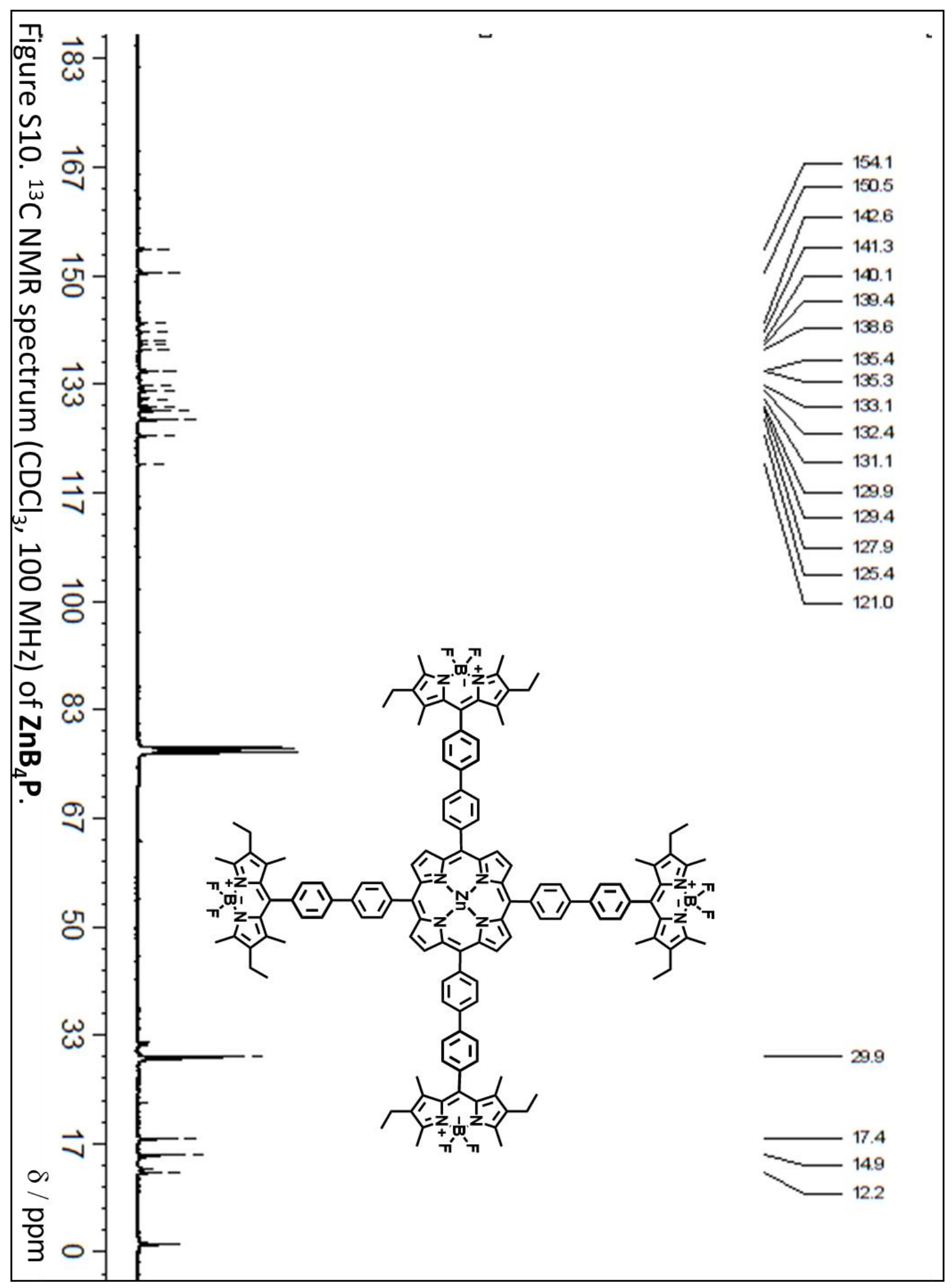




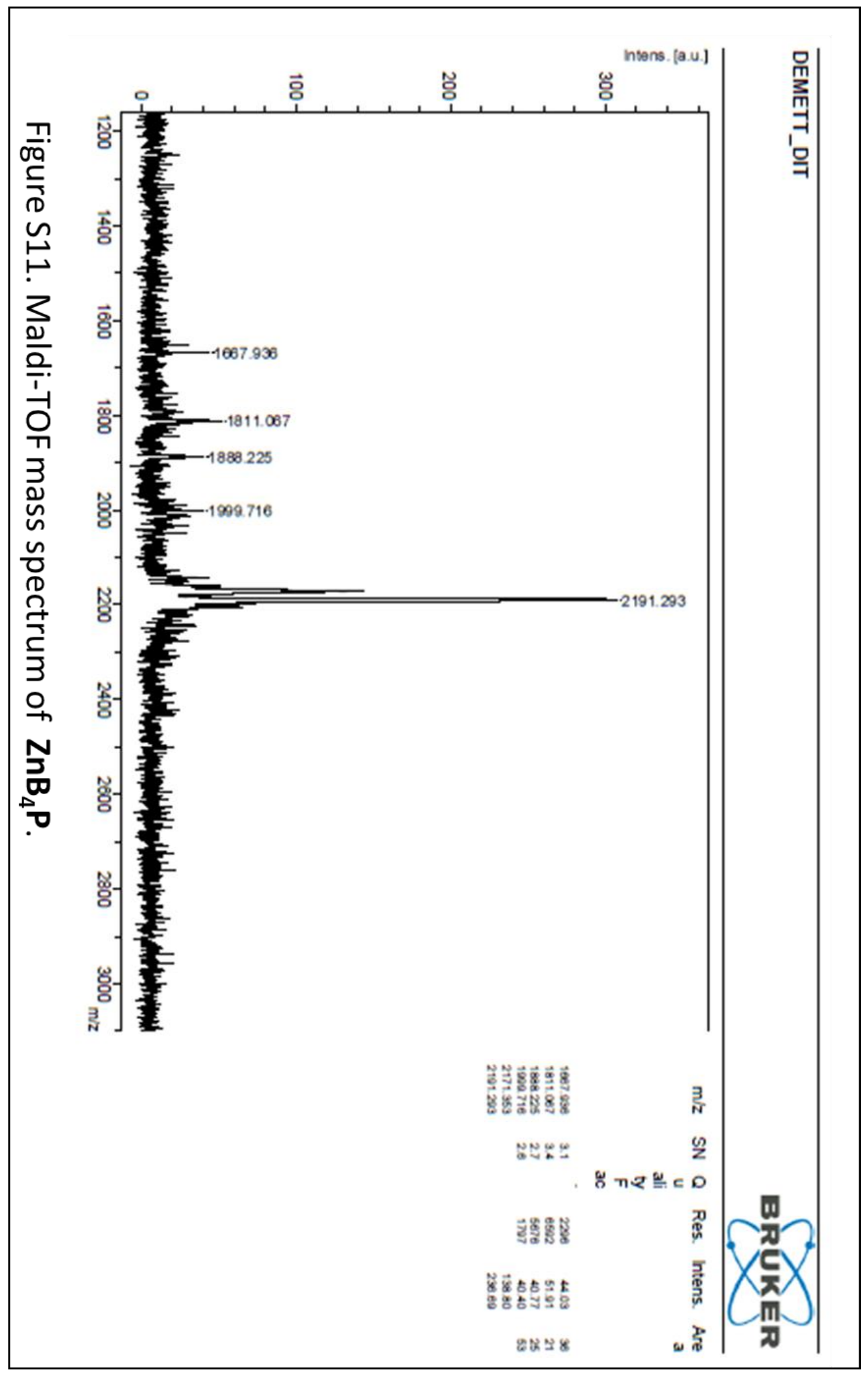




\section{S2. Overlap integrals and calculated rate constants for EET}

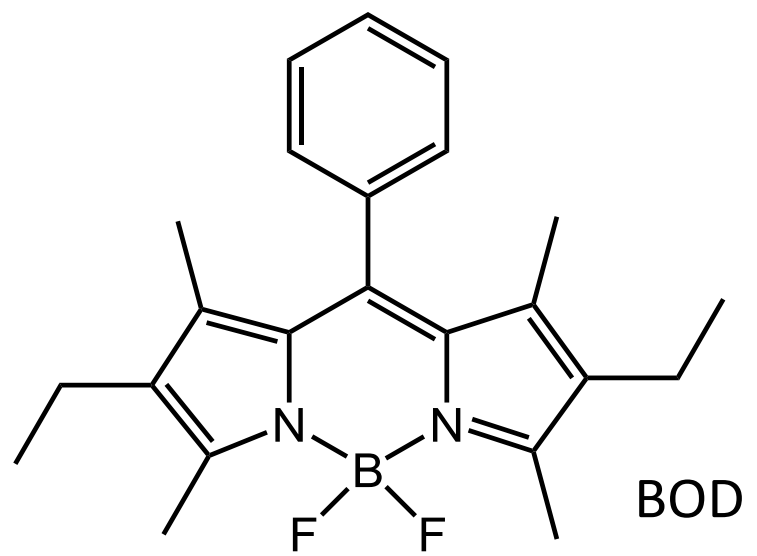

Chart S1. Molecular formula for the BODIPY-based control compound, BOD.

It is assumed here that EET from the $S_{1}$ state of BOD (Chart S1) to the corresponding $\mathrm{S}_{1}$ state of $\mathrm{ZnP}$ takes place exclusively by way of the dipole-dipole mechanism as outlined by Förster. ${ }^{\text {S2 }}$ This assumption eliminates a contribution from through-bond electron exchange, ${ }^{\mathrm{S} 3}$ although the latter might amplify the overall rate constant. The justification for neglecting electron exchange is based on the presumed poor electronic coupling between the $\mathrm{ZnP}$ and $\mathrm{BOD}$ subunits imposed by the meso-linkages ${ }^{\mathrm{S4}}$ and the mutual rotation of the bridging phenylene rings. ${ }^{S 5}$ Since triplet-triplet EET does occur, albeit on a greatly reduced timescale, by way of electron exchange, ${ }^{56}$ it is clear that the assumption is not entirely valid. It is applied here merely to provide a crude estimate for the likely rate of intramolecular EET.

$$
k_{E E T}=\frac{\left|V_{D A}\right|^{2}}{\hbar^{2} c} J_{D A}
$$

The rate constant ( $\mathrm{KEET}_{\mathrm{E}}$ ) for EET from BOD to $\mathrm{ZnP}$ is expressed by way of Equation $\mathrm{S} 1$, where JDA is the spectral overlap integral and $V_{D A}$ is the corresponding electronic coupling matrix element for Coulombic interactions. ${ }^{S 7}$ The overlap integral is obtained by integration of reduced absorption and emission spectra according to Equations S2 and $\mathrm{S} 3$, where $v$ refers to wavenumber, $\varepsilon \mathrm{A}(v)$ is the molar absorption coefficient for the acceptor at that wavenumber and $f_{D}(v)$ is the fluorescence intensity at that wavenumber. ${ }^{S 8}$ In order to evaluate $V_{D A}$ it is necessary to obtain values for the transition dipole moments $(\mu)$ for donor and acceptor species. These values can be obtained $^{\mathrm{S9}}$ from analysis of the reduced absorption spectra according to Equation S4, where the solvent screening factor $s$ is defined by Equation S5. The solvent refractive 
index is indicated by the symbol $\mathrm{n}$ and $\mathrm{N}_{\mathrm{A}}$ refers to Avogadro's constant. The resultant transition dipole moments are 4.47 D and 2.78 D, respectively, for BOD and for $\mathrm{S}_{1}$ of $\mathrm{ZnP}$. The corresponding value for the $\mathrm{ZnP} \mathrm{S}_{2}$ state, obtained from analysis of the Soret absorption band, is $29.6 \mathrm{D}$.

$$
\begin{gathered}
J_{D A}=A B \int \frac{f_{D}(v)}{v^{3}} \times \frac{\varepsilon_{A}(v)}{v} d v \\
A \int \frac{f_{D}(v)}{v^{3}} d v=B \int \frac{\varepsilon_{A}(v)}{v} d v=1 \\
\mu^{2}=\frac{3000 \ln 10 \hbar c}{8 \pi^{3} N_{A}} \times \frac{n}{s^{2}} \times \int \frac{\varepsilon}{v} d v \\
s=\frac{3 n^{2}}{2 n^{2}+1}
\end{gathered}
$$

The coupling element for Coulombic interactions between donor and acceptor can now be evaluated from Equation $\mathrm{S} 6$ where $\kappa$ is the orientation factor and $\varepsilon_{0}$ is the permittivity of free space. Here, $R_{c c}(=13.5 \AA)$ refers to the distance between the centers of the respective transition dipole moment vectors, as determined from molecular models. In turn, the orientation factor is obtained from Equation S7. Here, $\alpha$ and $\beta$, respectively, refer to the angles tended between the transition dipole moment vector on donor and acceptor and the molecular axis, with the latter being defined by a line connecting the two centers. See Figure S12 for a simple representation. The term $\gamma$ refers to the angle between the two transition dipole moment vectors. According to Martenssen, ${ }^{S 10}$ the two-fold symmetry inherent to $\mathrm{ZnP}$ must be taken into account when considering the orientation factor. This leads to a doubling up the transition dipole moment vectors on the $\mathrm{ZnP}$ acceptor (Figure S12). The two vectors differ by a factor of $\pi / 2$. As such, the overall orientation factor has a value close to unity. $\mathrm{S} 10$

$$
\begin{gathered}
V_{D A}=\frac{\mu_{D} \mu_{A}}{4 \pi \varepsilon_{0}} \times \frac{\kappa}{s^{2} R_{C C}^{3}} \\
\kappa^{2}=(\cos (\gamma)-3 \cos (\alpha) \cos (\beta))^{2}
\end{gathered}
$$




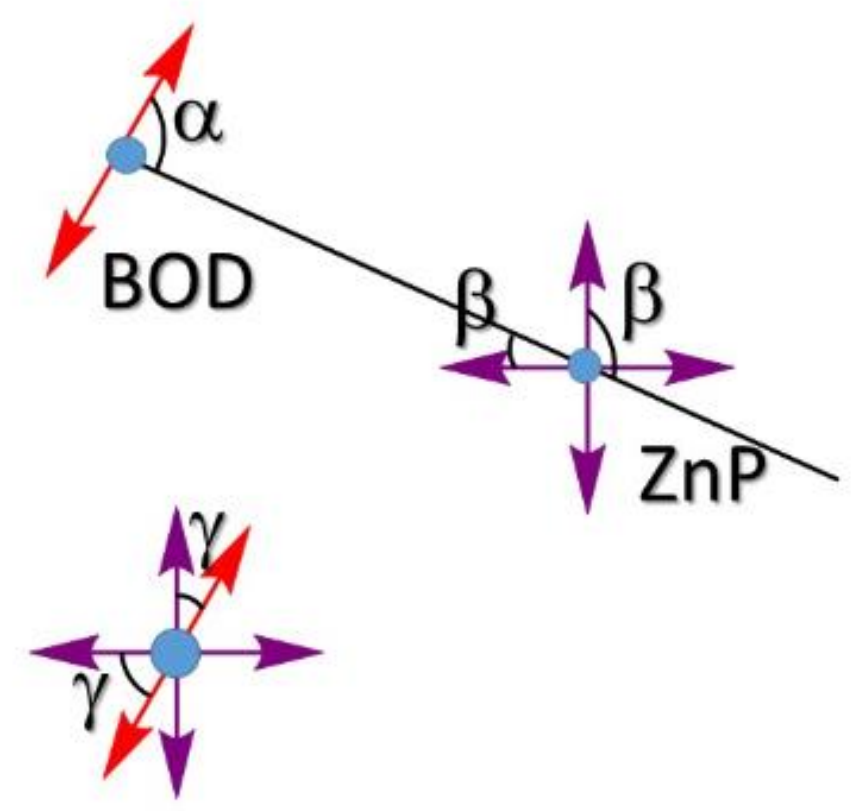

Figure S12. Simple illustration of the angles needed to calculate the orientation factor. The arrows refer to individual transition dipole moment vectors. The solid line represents the molecular axis. The lower cartoon refers to a situation in which the donor and acceptor have been superimposed onto a common point so as to illustrate the mutual angles between the vectors. Note that whereas the donor (red) has a single vector the $\mathrm{ZnP}$ acceptor (indigo) has two fold-symmetry and therefore two vectors need to be considered. 


\section{S3. Sensitization of BOD triplet state}

Laser excitation of BOD in de-aerated toluene at room temperature failed to generate a measureable yield of the triplet-excited state, regardless of excitation wavelength. Following addition of iodoethane (15\% v/v), transient bleaching of the ground-state absorption bands occurred but the sample appeared unstable over multiple laser pulses. Instead, access to the BOD T 1 state was realized by way of triplet-triplet energy transfer (TET) with benzophenone (BP) as the electronic energy donor. Figure S13 shows an example of a triplet-triplet transient absorption spectral profile recorded after laser excitation of BP in de-aerated toluene at $355 \mathrm{~nm}$. The spectrum is in good agreement with literature reports ${ }^{\mathrm{S} 11}$ and with the spectrum recorded by pulse radiolysis. ${ }^{\mathrm{S} 12}$ The triplet lifetime $(\tau \mathrm{T})$ recorded under these conditions is $3.1 \pm 0.2 \mu \mathrm{S}$ and decay restores the pre-pulse baseline (Figure S14). The initial absorbance, extrapolated to zero time from the first-order decay curves, was found to be a linear function of the laser power as adjusted with a series of screen filters (Figure S15). The differential molar absorption coefficient for triplet BP at $525 \mathrm{~nm}$ has been reported by Land and Bensasson ${ }^{\mathrm{S13}}$ as being $7,220 \pm 320 \mathrm{M}^{-1} \mathrm{~cm}^{-1}$.

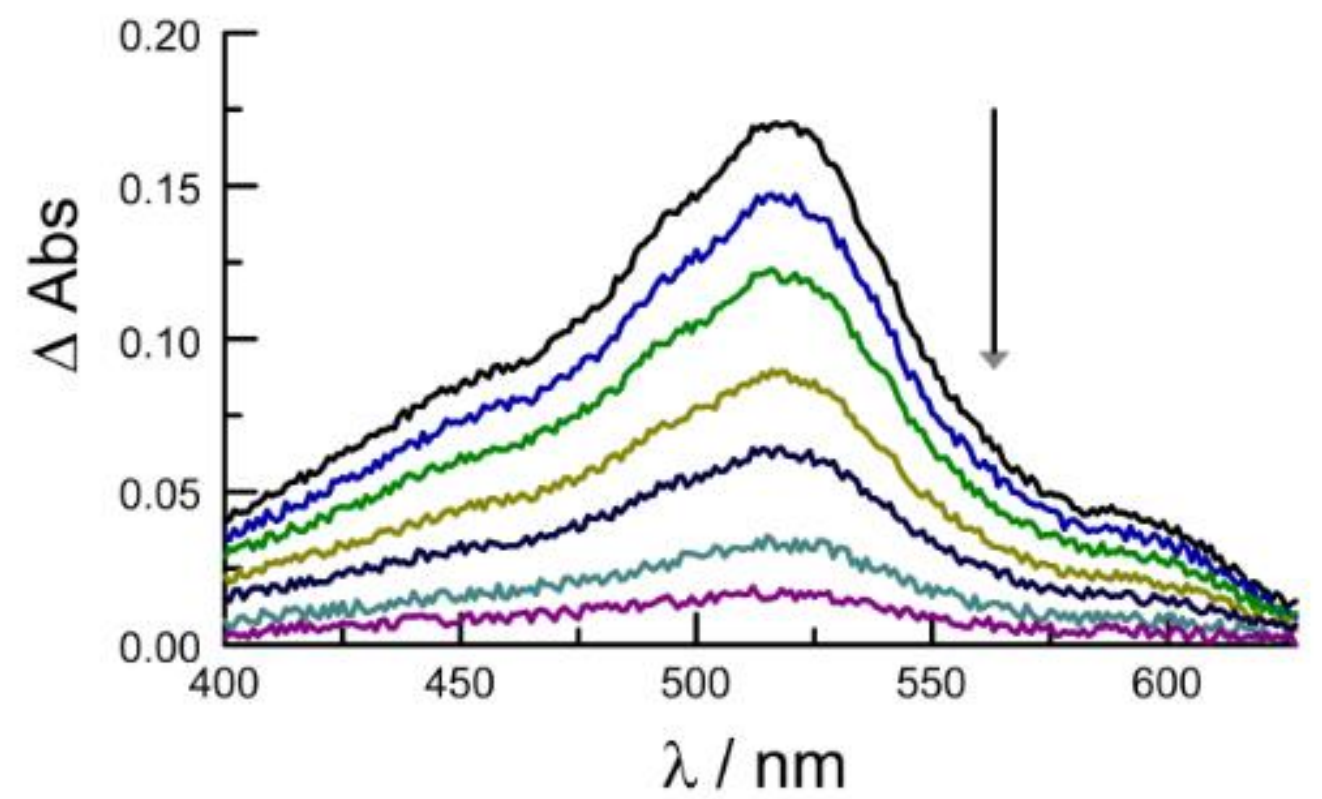

Figure S13. Transient differential absorption spectra recorded for the $T_{1}$ state of benzophenone in de-aerated toluene at room temperature with a 4-ns laser pulse at $355 \mathrm{~nm}$. Individual spectra were recorded at delay times of $70 \mathrm{~ns}, 500 \mathrm{~ns}, 1.1 \mu \mathrm{s}, 2.0$ $\mu \mathrm{s}, 3.0 \mu \mathrm{s}, 5.0 \mu \mathrm{s}$ and $7.0 \mu \mathrm{s}$. 


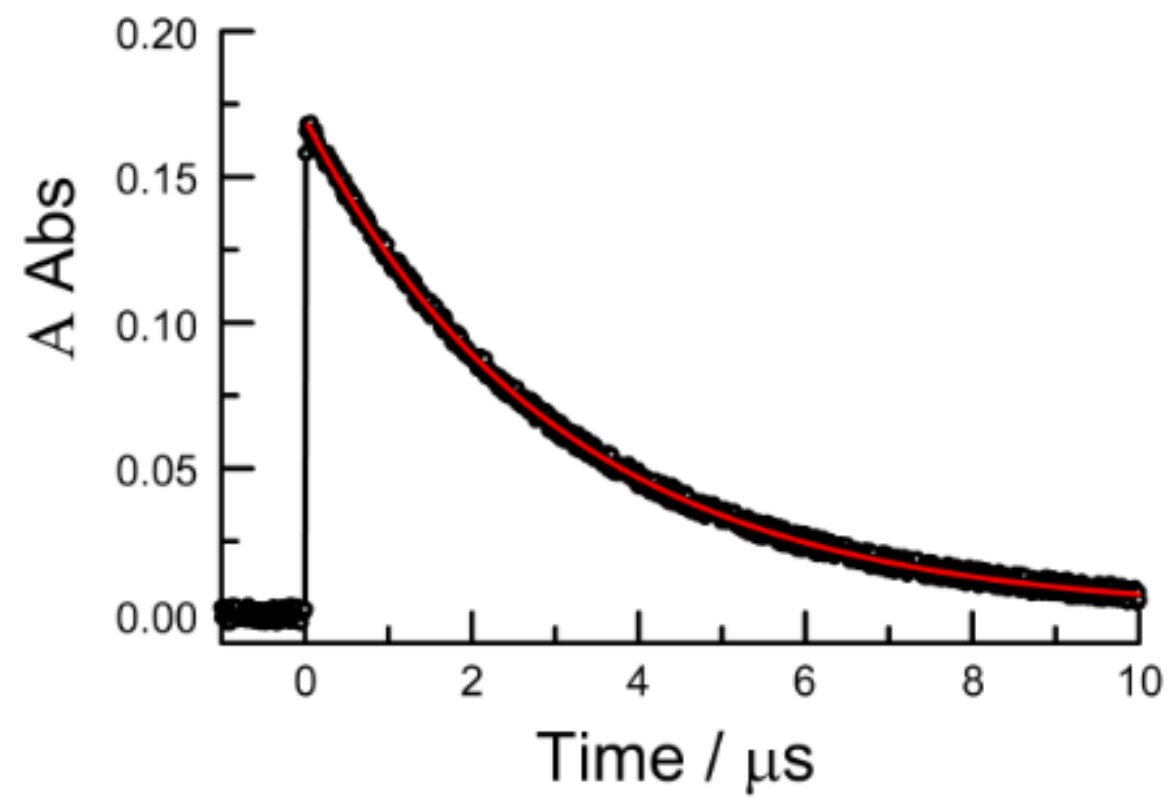

Figure S14. Example of a decay trace recorded for triplet benzophenone in de-aerated toluene following excitation at $355 \mathrm{~nm}$. The detection wavelength was $525 \mathrm{~nm}$. The fit to first-order kinetics is shown as a red line superimposed over the experimental data and corresponds to a triplet lifetime of $3.1 \pm 0.2 \mu \mathrm{s}$.

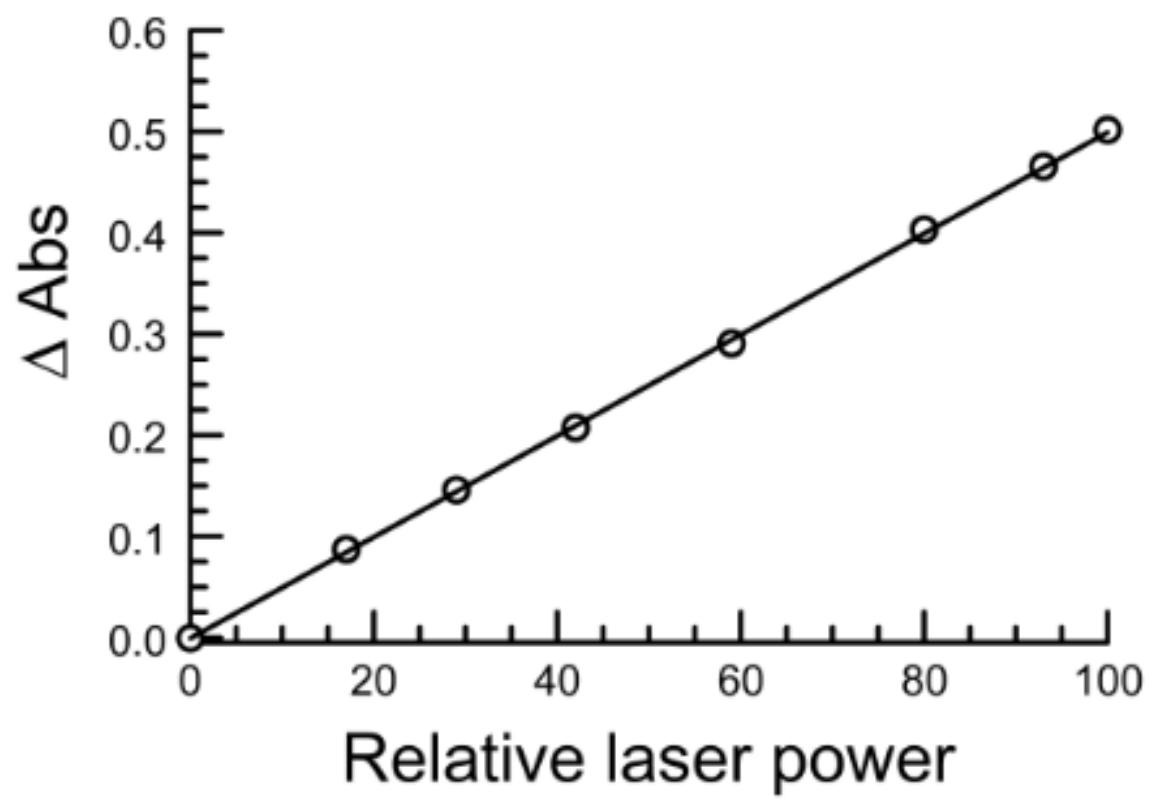

Figure S15. Effect of incident laser power on the absorbance change measured at 525 $\mathrm{nm}$ for triplet benzophenone in de-aerated toluene solution. 
Addition of BOD to the above solution causes a decrease in the measured $\tau$ T at 525 $\mathrm{nm}$. The experiment is somewhat complicated by the fact that BOD absorbs strongly at this wavelength. This necessitated the use of a thin optical cell to prevent saturation. The triplet lifetime for BP was measured across a range of BOD concentrations (Figure 16 ), with the observed first-order decay rate constant (KOBSD) giving a good fit to Equation S8. Here, $\mathrm{k}_{\mathrm{T}}$ is the reciprocal of $\tau$ T measured in the absence of $\mathrm{BOD}$ and $\mathrm{kQ}_{\mathrm{Q}}$ is the bimolecular rate constant for triplet-triplet energy transfer. Analysis of Figure $\mathrm{S} 16$ allows estimation of $\mathrm{kQ}$ as being $7 \pm 1 \times 10^{9} \mathrm{M}^{-1} \mathrm{~s}^{-1}$, which is somewhat lower than the diffusion controlled rate limit. Comparison of koBs with Equation S9 allows calculation of the triplet energy transfer probability (РтT) as a function of BOD concentration. At the highest acceptor concentration available to us, the maximum $\mathrm{P}_{\mathrm{TT}}$ value reached corresponds to ca. $60 \%$. The ratio of maximum absorbance values for triplet BP, found by extrapolation of the first-order decay rate constant, and triplet BOD, obtained by fitting the transient signal in the bleaching region, can be used to determine the differential molar absorption coefficient for triplet BOD at $525 \mathrm{~nm}$ (Figures S17 and S18). The derived value, averaged across a series of laser powers, was found to be $69,400 \pm 2,900 \mathrm{M}^{-1} \mathrm{~cm}^{-1}$ (Figure S19). The triplet lifetime for BOD under these conditions is $70 \pm 5 \mu \mathrm{s}$ (Figure S18). The transient differential absorption spectrum recorded for BOD shows important isosbestic points at $468 \mathrm{~nm}$ and at $550 \mathrm{~nm}$ (Figure S17). 


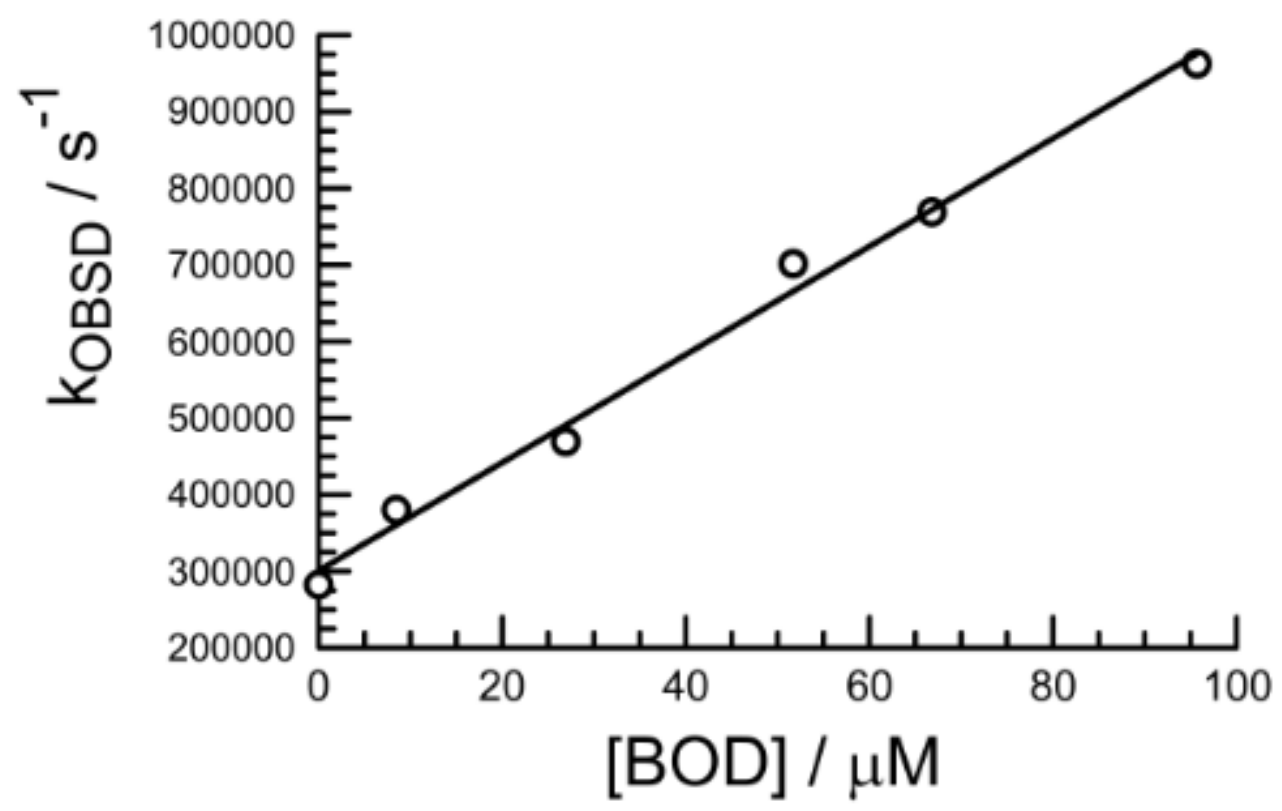

Figure S16. Effect of added BOD on the rate constant for deactivation of triplet benzophenone in de-aerated toluene. The signal was monitored at $470 \mathrm{~nm}$ which is close to being an isobestic point for triplet BOD. The fit to the experimental data points refers to Equation S8 and corresponds to a bimolecular rate constant for triplet-triplet energy transfer of $7 \pm 1 \times 10^{9} \mathrm{M}^{-1} \mathrm{~s}^{-1}$.

$$
k_{O B S D}=k_{T}+k_{Q}[B O D]
$$




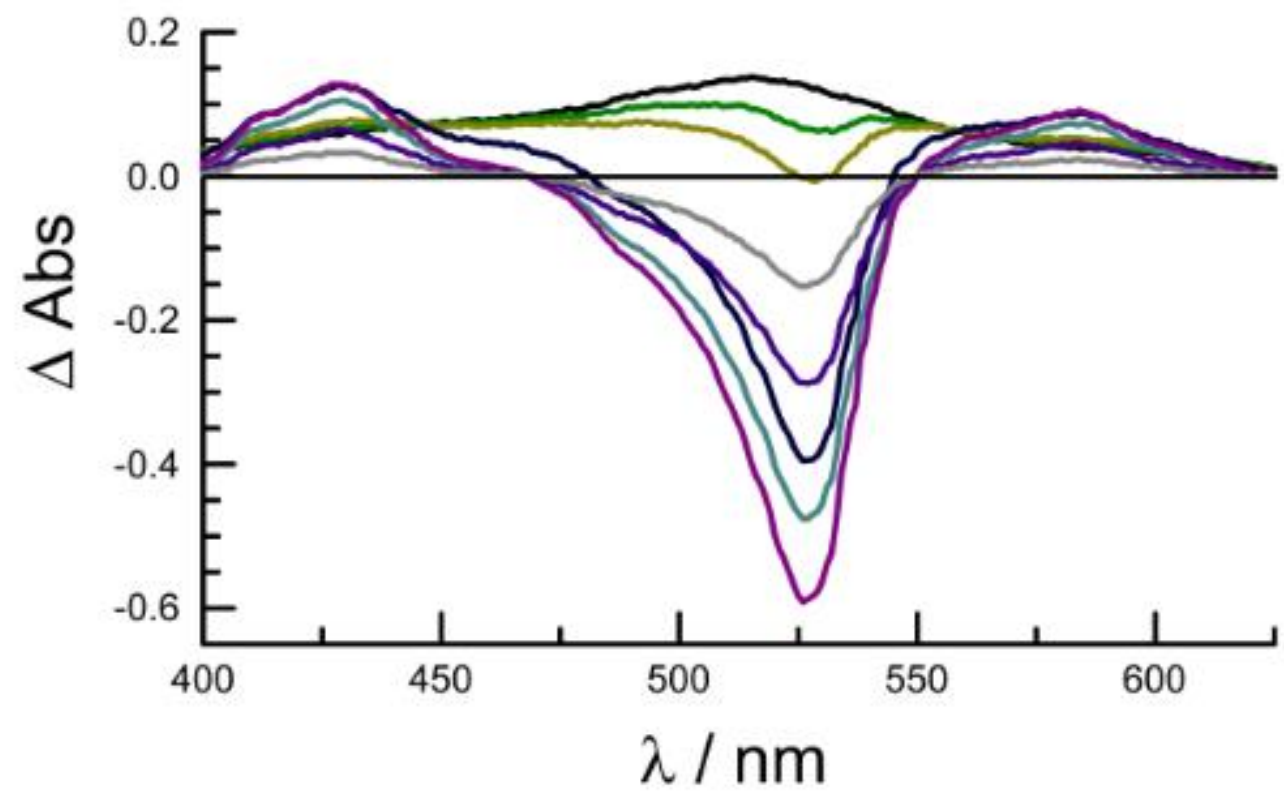

Figure S17. Transient differential absorption spectra recorded after laser excitation of benzophenone in de-aerated toluene containing BOD $(70 \mu \mathrm{M})$ in a $1 \mathrm{~mm}$ optical cell. Under these conditions, $\mathrm{P}_{\mathrm{EET}}$ is ca. $60 \%$. Individual spectra were recorded at delay times of 20 ns (black), 50 ns (green), 100 ns (khaki), 200 ns (grey), $1 \mu \mathrm{s}$ (light blue), $25 \mu \mathrm{s}$ (indigo), $40 \mu$ s (royal blue) and $75 \mu$ s (purple). The initial spectrum, showing absorption around $525 \mathrm{~nm}$, is assigned to triplet benzophenone while the later spectra, showing bleaching around $525 \mathrm{~nm}$, are assigned to triplet BOD.
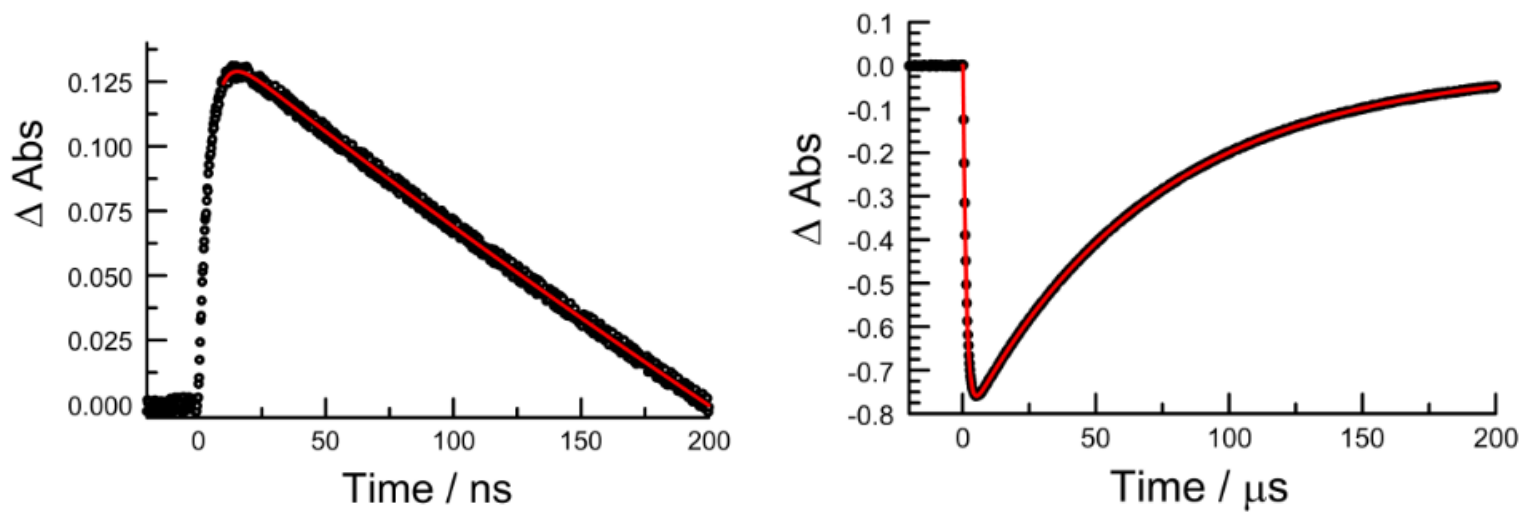

Figure S18. Kinetic traces recorded for the experiment described above. The decay kinetics were monitored at $525 \mathrm{~nm}$ on two disparate timescales. The left-hand panel refers to deactivation of triplet benzophenone while the right-hand panel refers to formation and subsequent decay of triplet BOD. In each case, the red curve drawn 
through the data points represents a non-linear, least-squares fit to successive firstorder processes. The triplet lifetime for benzophenone is calculated to be $1.23 \mu \mathrm{s}$ while that for BOD is $70 \mu \mathrm{s}$.

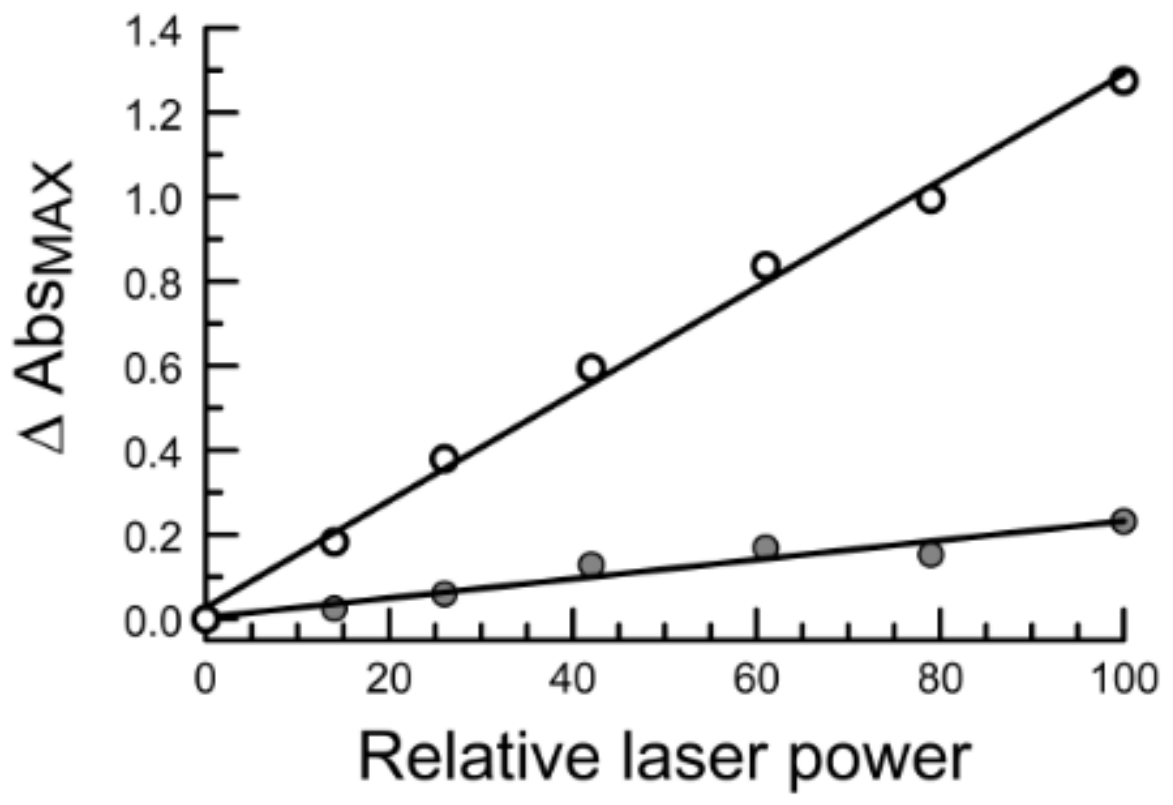

Figure S19. Effect of incident laser power on the maximum absorbance assigned to triplet benzophenone (filled circles) and triplet BOD (open circles) at $525 \mathrm{~nm}$. The latter absorbance change is shown as a positive signal for convenience. The maximum absorbance data were extracted from fits to two successive first-order processes as shown above. The ratio of absorbance changes is 0.173 and, taken together with $\mathrm{PEET}_{\mathrm{EE}}$ $=60 \%$, allows estimation of the molar absorption coefficient for triplet BOD.

$$
P_{E E T}=\frac{k_{Q}[B O D]}{k_{Q}[B O D]+k_{T}}
$$




\section{S4. Studies with $\mathrm{FbPB}_{4}$}

Samples of the free-base porphyrin analogue, $\mathrm{FbPB}_{4}$, were prepared by careful demetallation of $\mathrm{ZnPB}_{4}$ using a stock solution of $\mathrm{HCl}$ in dioxane (Sigma-Aldrich). After neutralization with aqueous $\mathrm{NaHCO}_{3}$ solution, washing with water and drying over $\mathrm{CaCl}_{2}$, the solution was evaporated to dryness using a stream of $\mathrm{N}_{2}$. The molar absorption coefficient was determined by direct comparison to that of $\mathrm{ZnPB}_{4}$ by way of quantitative demetallation as above. The quoted value is the average of three separate measurements. Molar absorption coefficients for the free-base porphyrin, FbTPP, were taken from the literature. ${ }^{\mathrm{S} 14} \mathrm{An}$ example of an absorption spectrum recorded for $\mathrm{FbPB}_{4}$ in toluene solution is shown as Figure S20 while the corresponding fluorescence spectrum is given as Figure S21. The fluorescence quantum yield for the FbP unit was measured relative to FbTPP in air-equilibrated toluene $\left(\Phi_{\mathrm{F}}=0.11\right)^{\mathrm{S} 15}$ with an excitation wavelength of $512 \mathrm{~nm}$. The excited-singlet state lifetime ( $\tau \mathrm{s}=8.4 \mathrm{~ns}$ ) for the FbP unit was measured by phase modulation fluorescence spectroscopy with an excitation wavelength of $420 \mathrm{~nm}$. The quantum yield for emission from the BOD unit is described later in the ESI. An example of an excitation spectrum recorded for fluorescence from the $\mathrm{FbP}$ unit is provided as Figure S22.

The spectral overlap integral for absorption by the Q-band region of $\mathrm{FbP}$ and fluorescence from the BOD unit was determined as described earlier for $\mathrm{ZnPB}_{4}$. The normalized reduced spectra are compared in Figure S23, giving an overlap integral of $1.53 \times 10^{-4} \mathrm{~cm}$. Assuming the same separation distance and orientation factor as derived for $\mathrm{ZnPB}_{4}$, the rate constant for $\mathrm{EET}$ from $\mathrm{BOD}$ to $\mathrm{FbP}$ is estimated from Equation $\mathrm{S} 1$ as being $5.1 \times 10^{10} \mathrm{~s}^{-1}$.

An example of a triplet-triplet absorption spectrum recorded ${ }^{\mathrm{S} 16}$ for FbTPP in deaerated toluene at room temperature is given as Figure S24. The triplet lifetime recorded at $440 \mathrm{~nm}$ following excitation with a 4-ns laser pulse at $532 \mathrm{~nm}$ was found to be $240 \mu \mathrm{s}$. The differential absorbance measured at $440 \mathrm{~nm}$ depends linearly on incident laser power under these conditions. At high laser powers, the decay curve deviates from first-order kinetics due to the onset of triplet-triplet annihilation. A useful isosbestic point for the transient differential absorption spectrum is found at $529 \mathrm{~nm}$, where the $T_{1}$ state of $B O D$ is known to display a strong negative signal. 

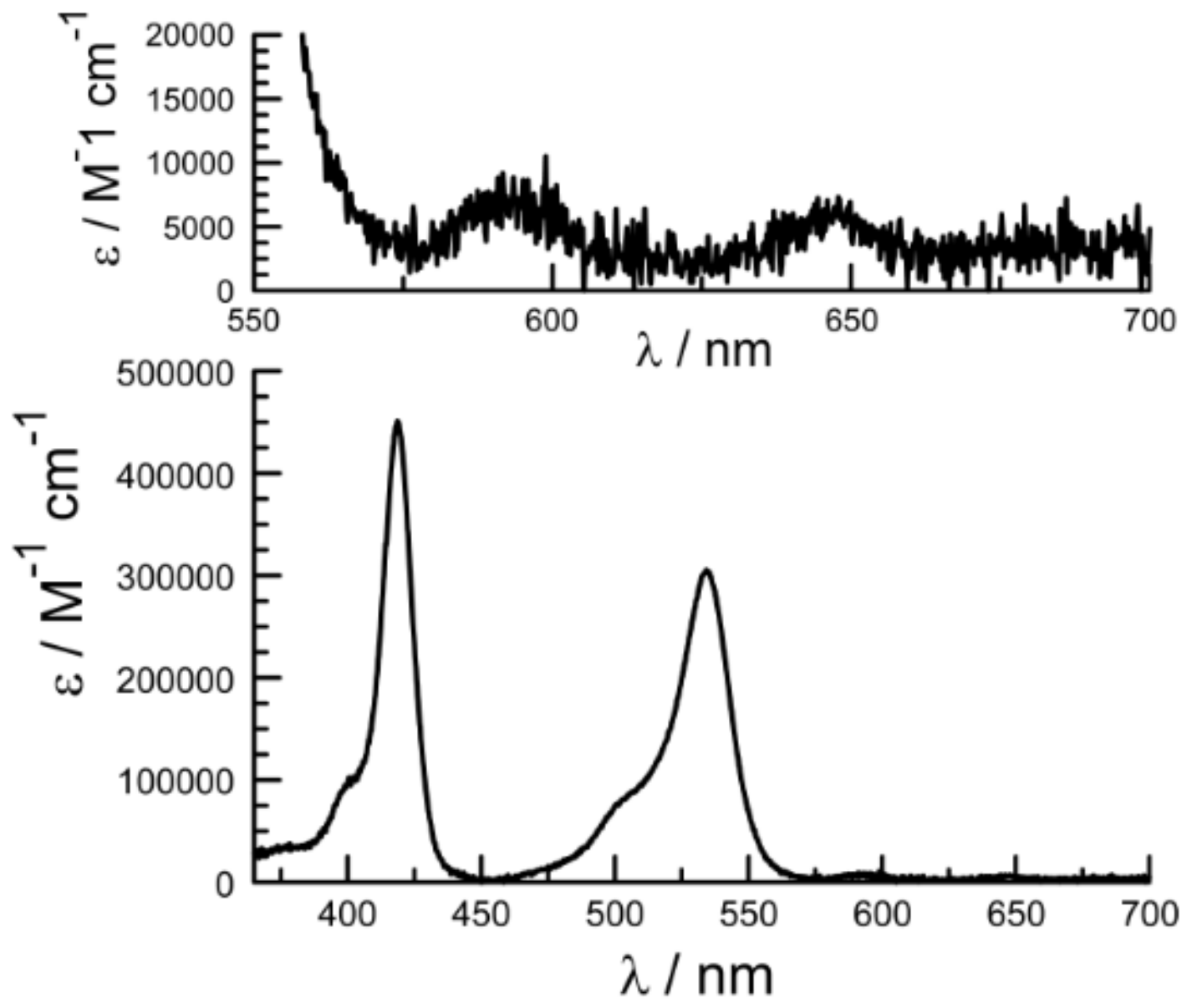

Figure S20. Example of an absorption spectrum recorded for $\mathrm{FbPB}_{4}$ in toluene solution at room temperature. The lower panel shows the entire spectrum, with average molar absorption coefficients indicated, and the prominent absorption signals for the FbP Soret band at $418 \mathrm{~nm}$ and the BODIPY $\pi, \pi^{*}$ transition at $530 \mathrm{~nm}$. The upper panel shows an enlargement of the FbP Q-band region. 


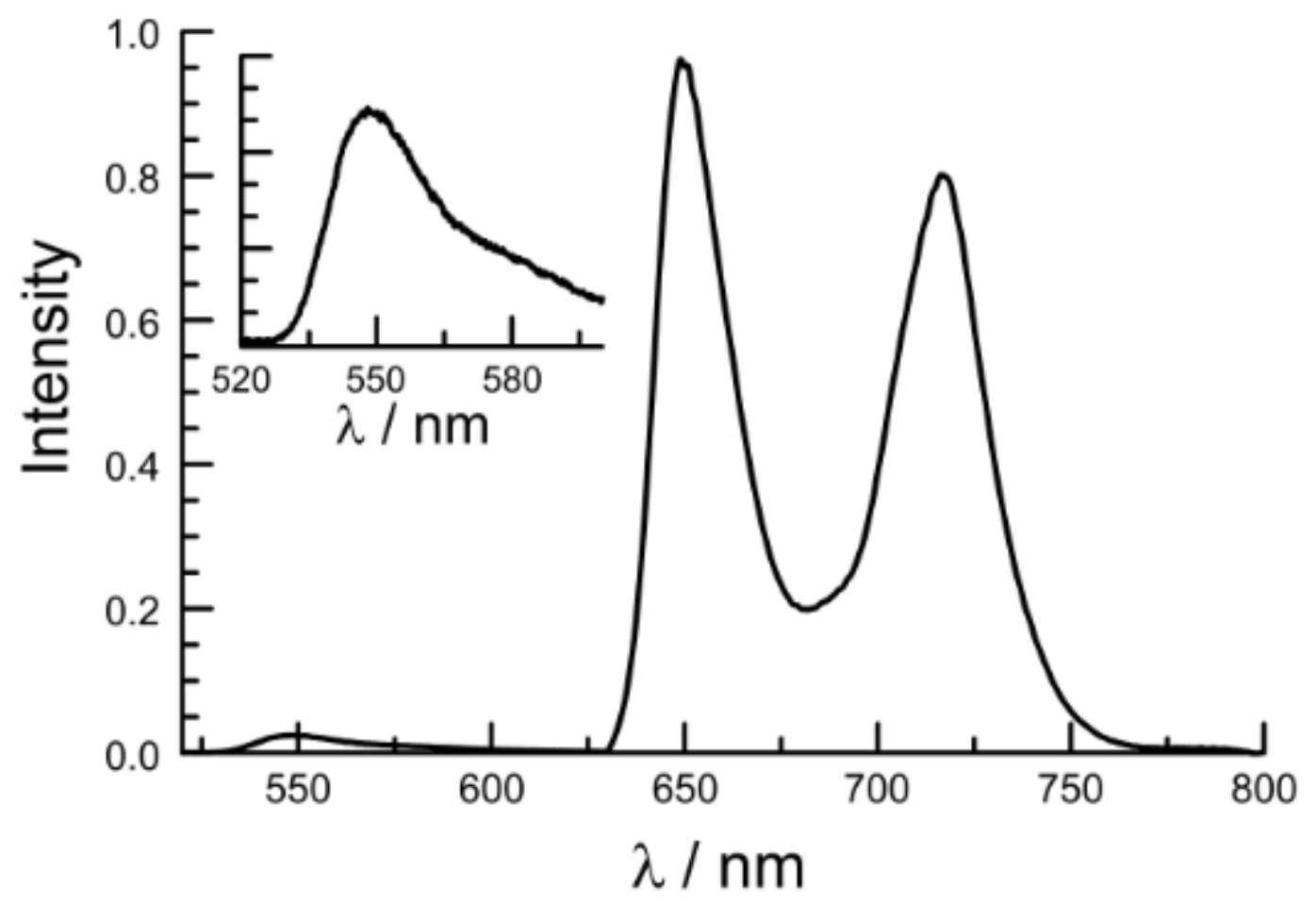

Figure S21. Example of a fluorescence spectrum recorded for $\mathrm{FbPB}_{4}$ in dilute toluene solution at room temperature. The excitation wavelength was $502 \mathrm{~nm}$, corresponding to preferential absorption by the BODIPY subunit. The insert shows an expansion of the emission profile attributed to residual fluoresence from the BODIPY unit. 

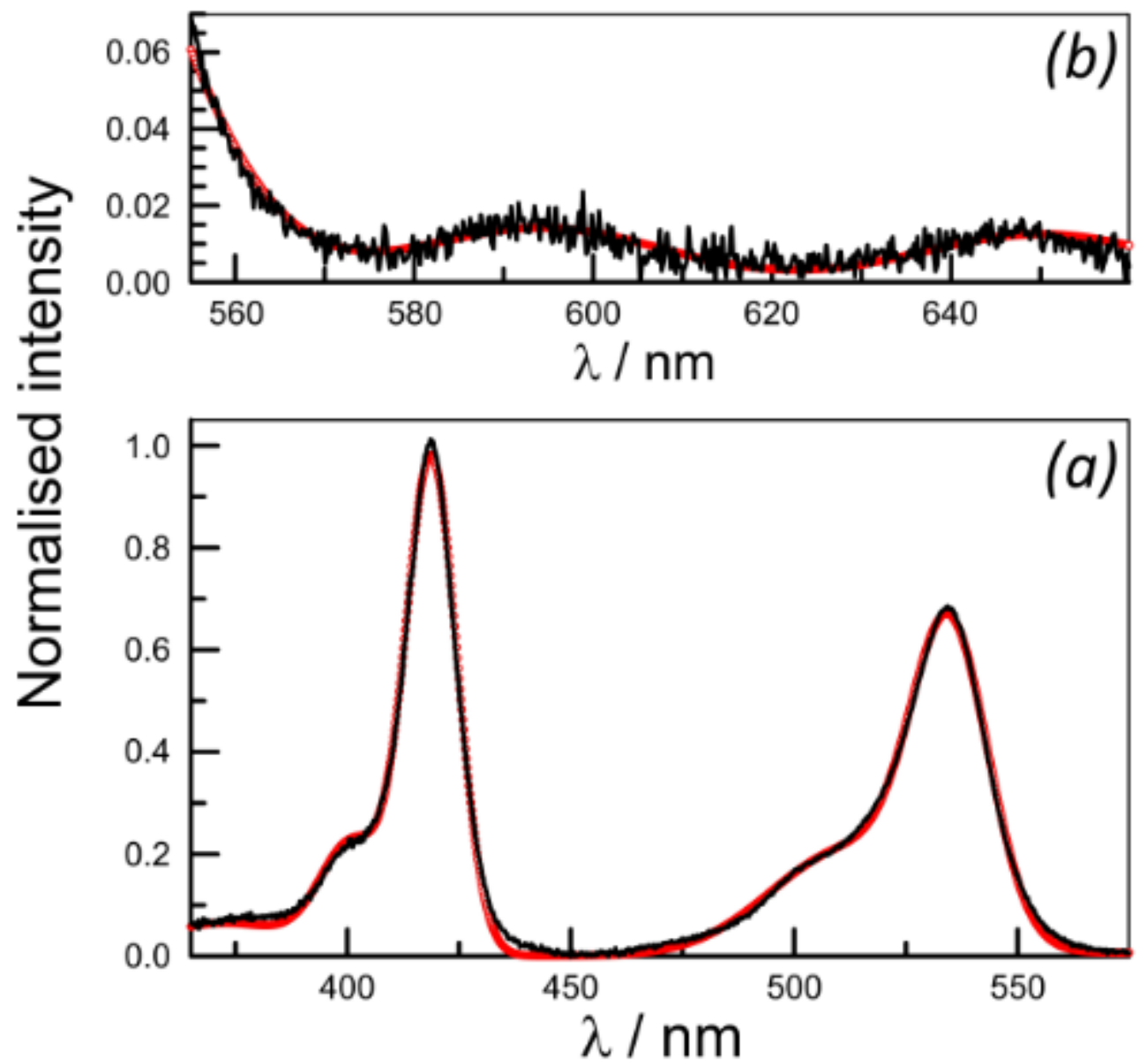

Figure S22. (a) Comparison of absorption (black curve) and excitation (red curve) spectra recorded for emission from $\mathrm{FbPB}_{4}$ in dilute toluene solution. The emission wavelength was $720 \mathrm{~nm}$. (b) Enlargement of the FbP Q-band region, using larger slit widths. Excitation spectra were the average of 5 separate runs and normalization was made in the region of the BOD absorption. 


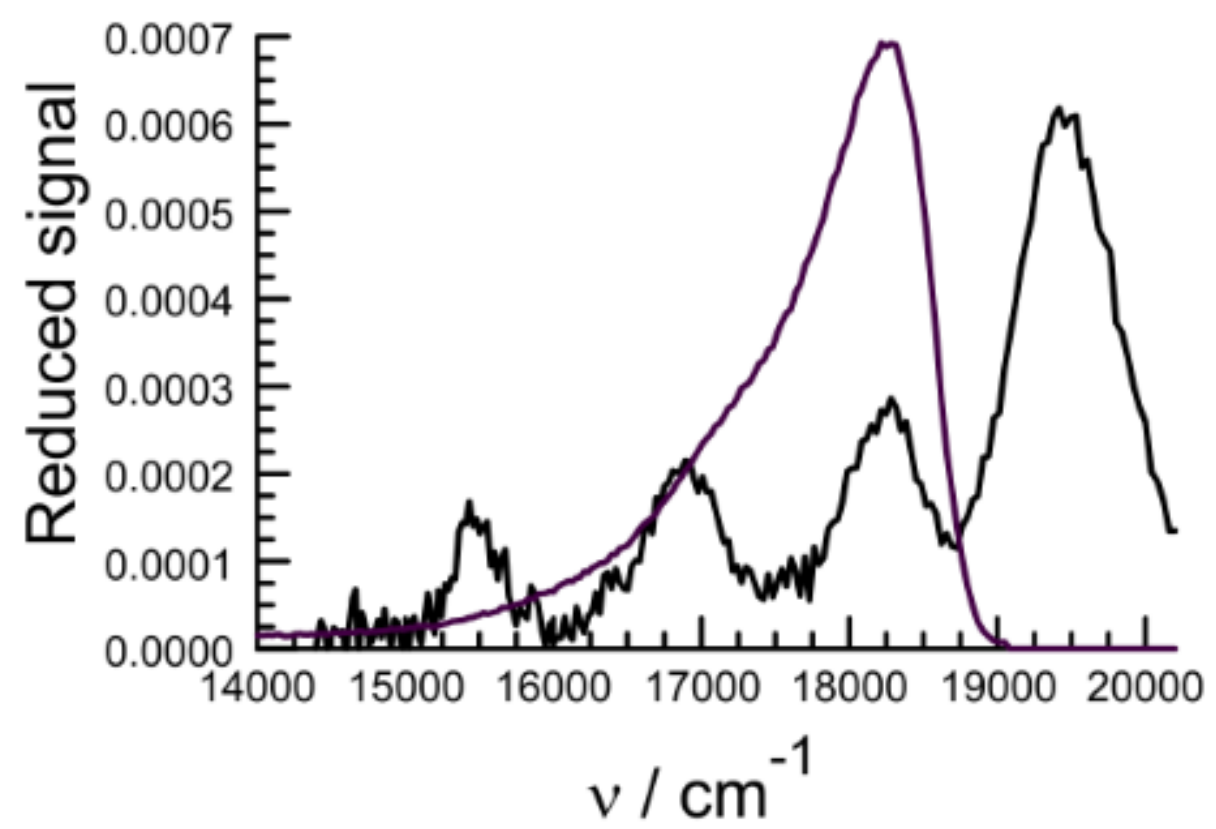

Figure S23. Spectral overlap between reduced spectra recorded for Q-band absorption by FbTPP (black curve) and fluorescence from BOD (indigo curve) used to calculate the overlap integral for EET from BOD to FbP. The solvent was toluene.

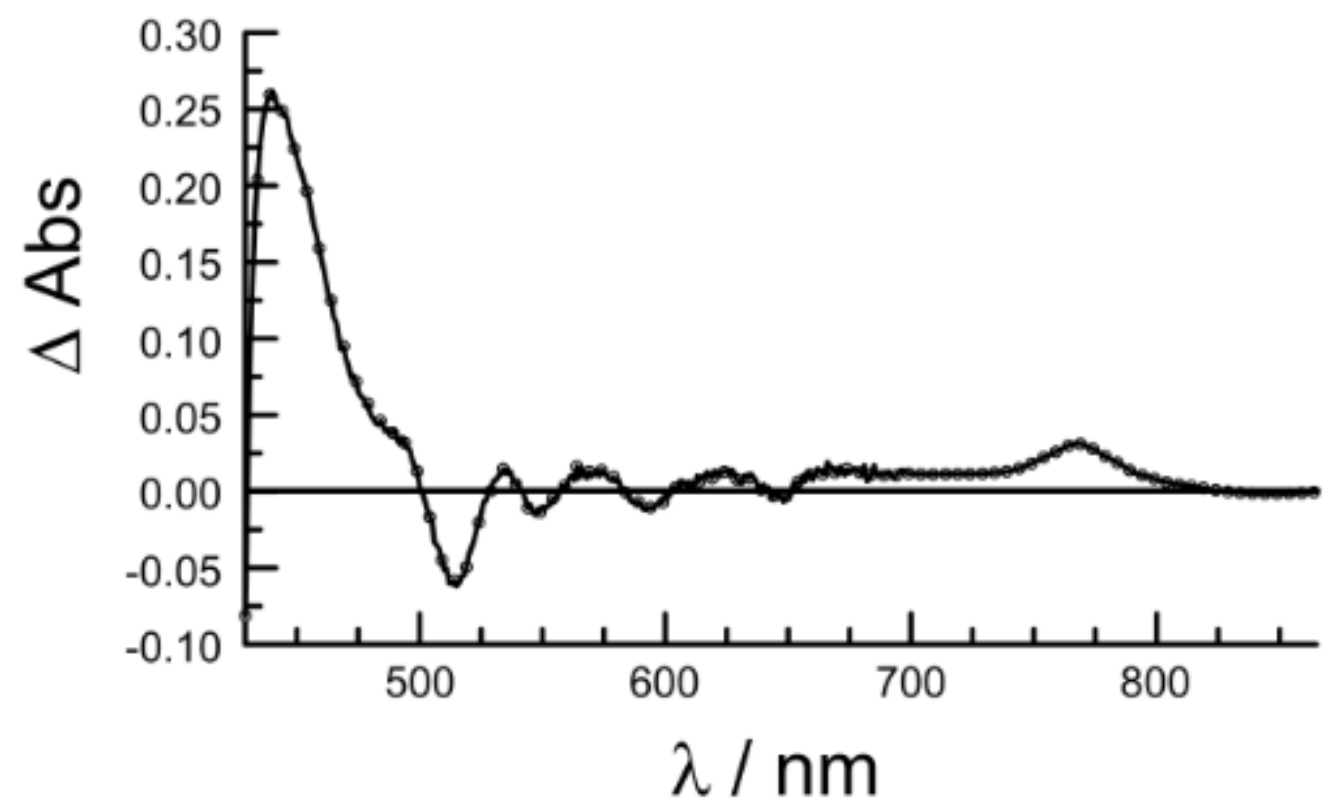

Figure S24. Transient differential absorption spectrum recorded after laser excitation of FbTPP in de-aerated toluene. The excitation wavelength was $420 \mathrm{~nm}$ and the spectrum was recorded $10 \mathrm{~ms}$ after the laser pulse. Note the isosbestic points at 501 and $529 \mathrm{~nm}$. 


\section{S5. Determination of the fluorescence quantum yield for weak signals}

Residual fluorescence from the BODIPY unit present in both $\mathrm{ZnPB}_{4}$ and $\mathrm{FbPB}_{4}$ was very weak and therefore difficult to quantify. Results obtained with the integrating sphere, which were highly reproducible for emission from the respective porphyrin units, were unsatisfactory in terms of reproducibility. Comparison with a weakly fluorescent BODIPY derivative, ${ }^{\text {S17 }}$ diphenyl-BODIPY (Chart S2), involved a large extrapolation and so this protocol was slightly amended. Rather than make a direct comparison between the two integrated fluorescence areas obtained under standardized conditions, the emission signal from the reference was attenuated with neutral density filters. For these studies, the absorbance at $500 \mathrm{~nm}$ was $0.070 \pm 0.002$. On the acceptance that, under these conditions, the emission integral is a linear function of the quantum yield, interpolation allows estimation of the $\Phi_{F}$ for the compound of interest (Figure S25). This approach leads to $\Phi_{F}$ values of 0.0008 and 0.003, respectively, for the BODIPY units present in $\mathrm{ZnPB}_{4}$ and $\mathrm{FbPB}_{4}$. The fluorescence quantum yield for reference compound in dioxane is $0.027 . \mathrm{S17}$

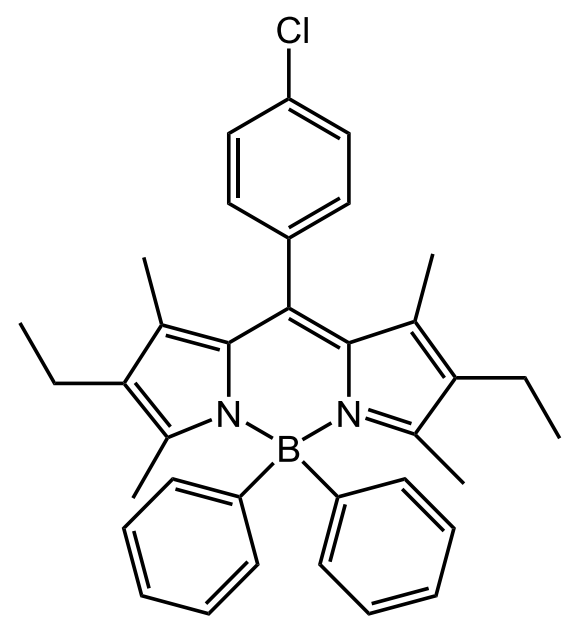

Chart S2. Molecular formula for the reference compound diphenyl-BODIPY. 


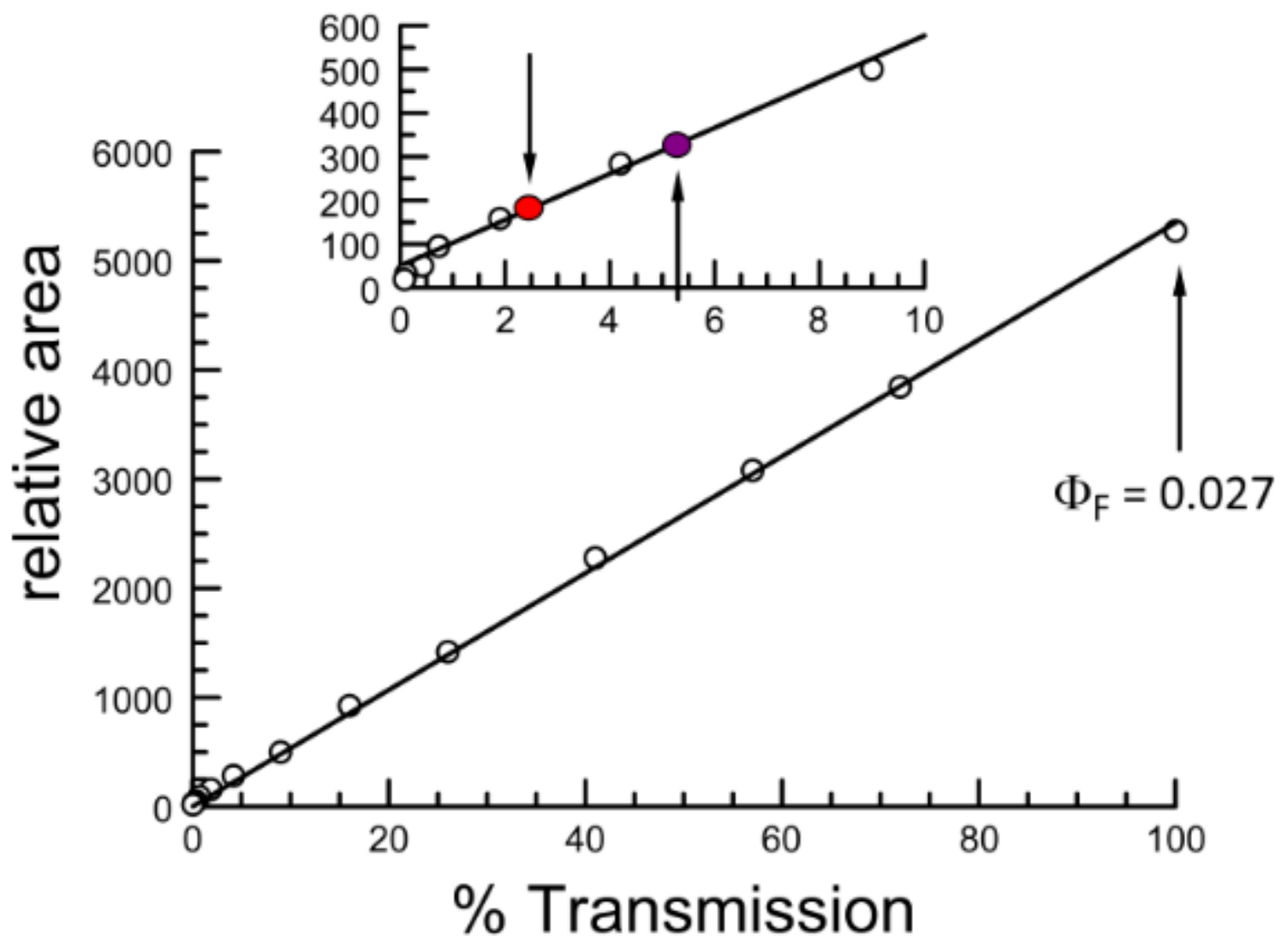

Figure S25. Illustration of the derivation of the fluorescence quantum yield for the BOD component present on the porphyrin-BODIPY clusters. The main panel shows successive attenutation of the fluorescence from the reference compound by insertion of neutral density filters between sample and detector. The initial quantum yield, in the absence of an attenuating filter, is 0.027 . Attenutation corresponds to a linear decrease in emission. The uppermost panel shows an expansion of the low transmission range with the emission areas obtained for $\mathrm{ZnPB}_{4}$ (red point) and $\mathrm{FbPB}_{4}$ (purple point), measuring only the spectral range relevant to $B O D$ and using optically matched solutions. The emission areas are interpreted in terms of percent transmission and compared to BD1. 
S6. Additional spectroscopic information
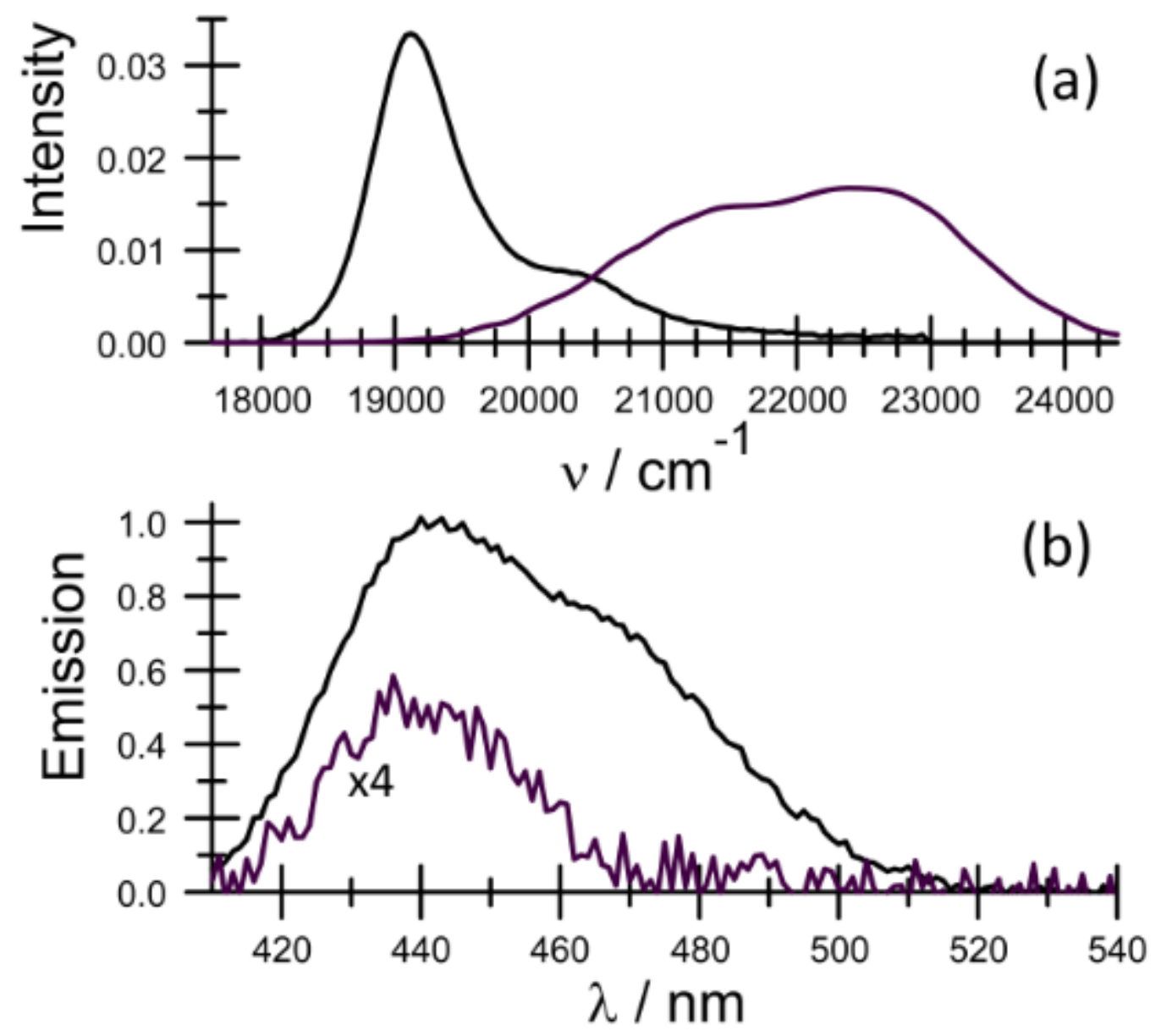

Figure S26. (a) Spectral overlap between the reduced absorption spectrum for BOD and the reduced fluorescence spectrum recorded for ZnTPP in toluene solution at room temperature. (b) Comparison of fluorescence spectral profiles recorded for ZnTPP (black curve) and $\mathrm{ZnPB}_{4}$ (indigo curve) following excitation at $390 \mathrm{~nm}$. The solutions were optically matched at $390 \mathrm{~nm}$. 


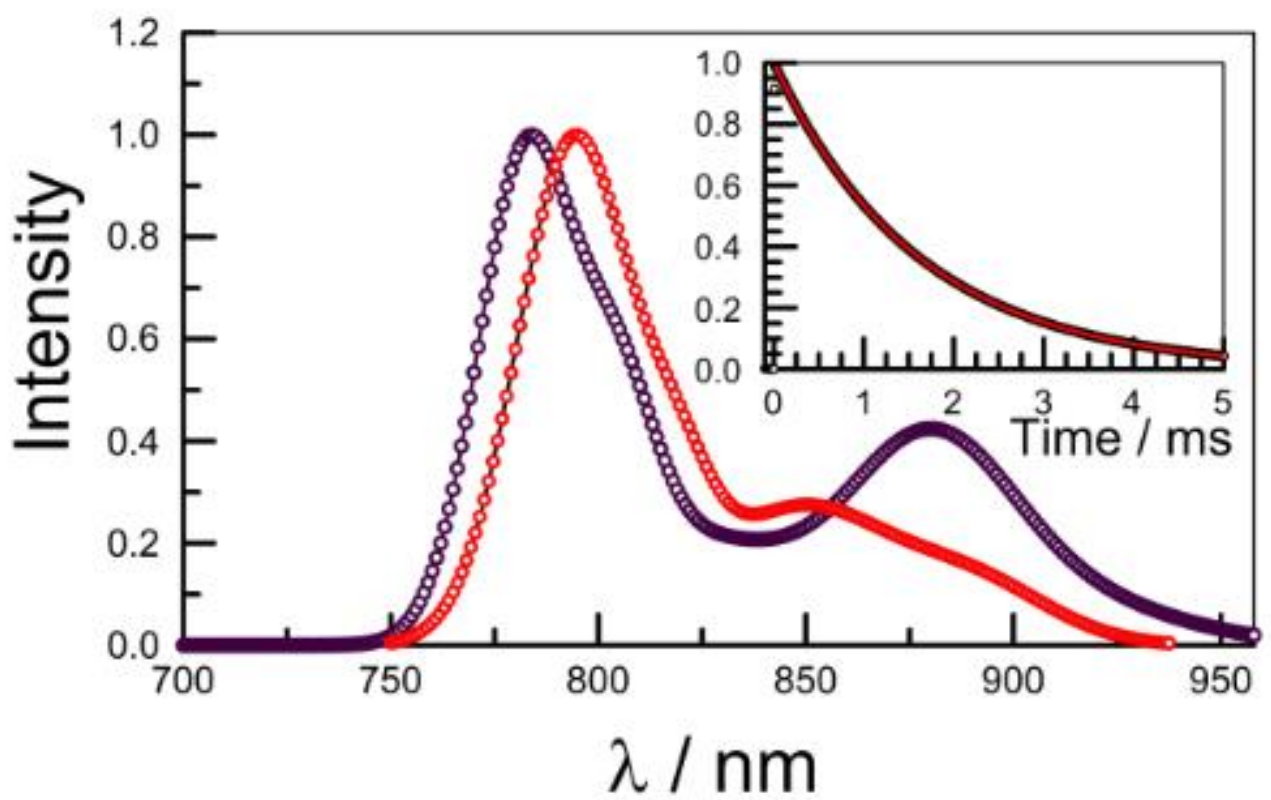

Figure S27. Phosphorescence spectra recorded for ZnTPP (indigo curve) and BOD (red curve) in an EPA glass at 77K. In the latter case, the solution contained iodoethane $(15 \% \mathrm{v} / \mathrm{v})$ as spin orbit accelerator. The spectra were normalized at the respective maxima. Also shown is an example of a kinetic trace recorded following excitation of ZnTPP with a 2 - $\mu$ s excitation pulse. The red line running through the data points corresponds to a nonlinear least-squares fit to an exponential process with a lifetime of $2.9 \mathrm{~ms}$. 


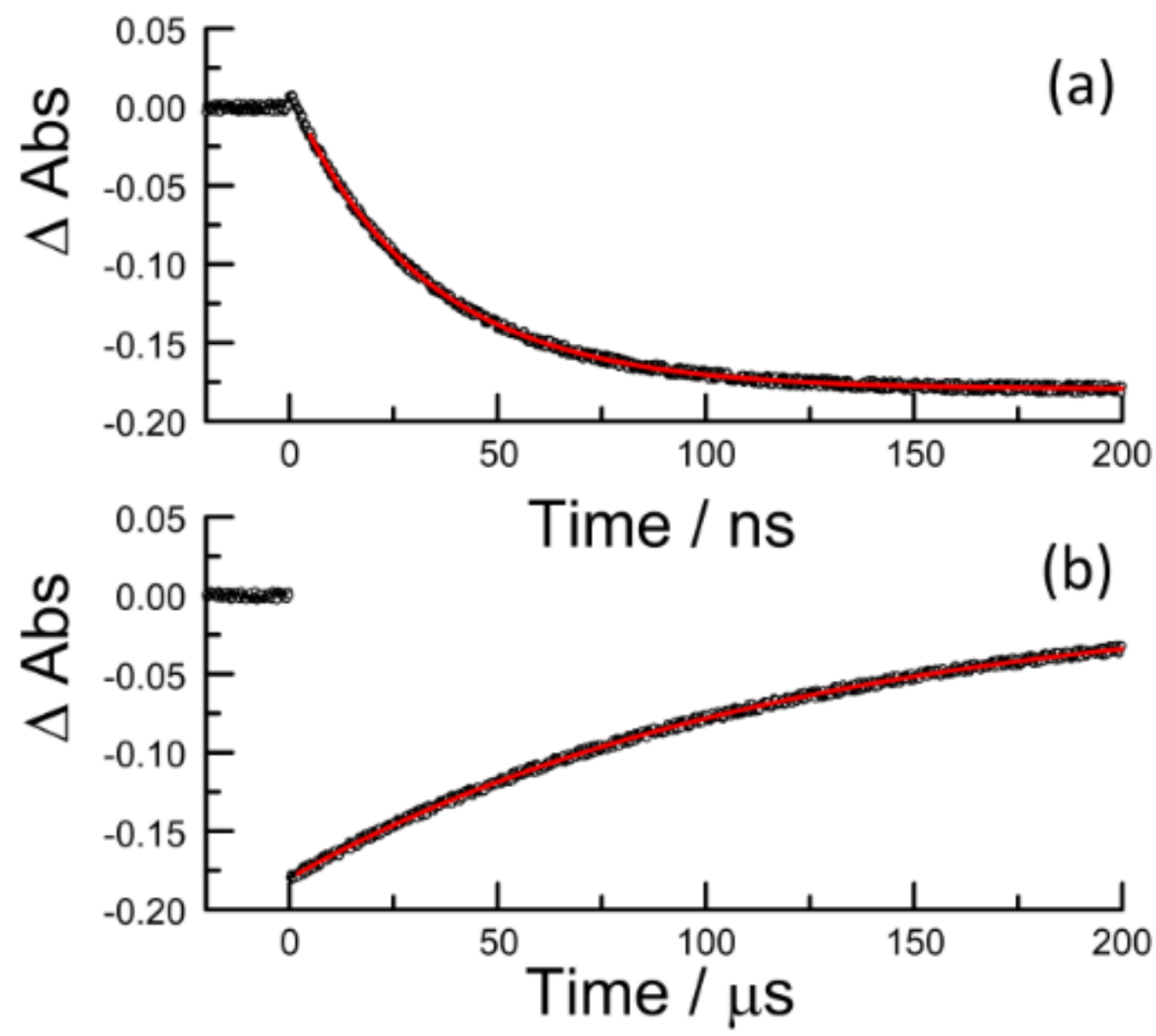

Figure S28. Examples of kinetic traces recorded at $540 \mathrm{~nm}$, this being an isosbestic point for the triplet state of $\mathrm{ZnP}$, following laser excitation of $\mathrm{ZnPB}_{4}$ in de-aerated toluene at $532 \mathrm{~nm}$. (a) Bleaching of the ground state due to triplet-triplet energy transfer from $\mathrm{ZnP}$ to BOD. The red line drawn through the data points corresponds to a firstorder process with a lifetime of $31 \mathrm{~ns}$. (b) Recovery of the transient ground-state bleaching of the BOD chromophore. The red line drawn through the experimental data points refers to an exponential process with a lifetime of $120 \mu \mathrm{s}$. For both experiments, the reported decay curve is the average of 250 individual laser shots. 


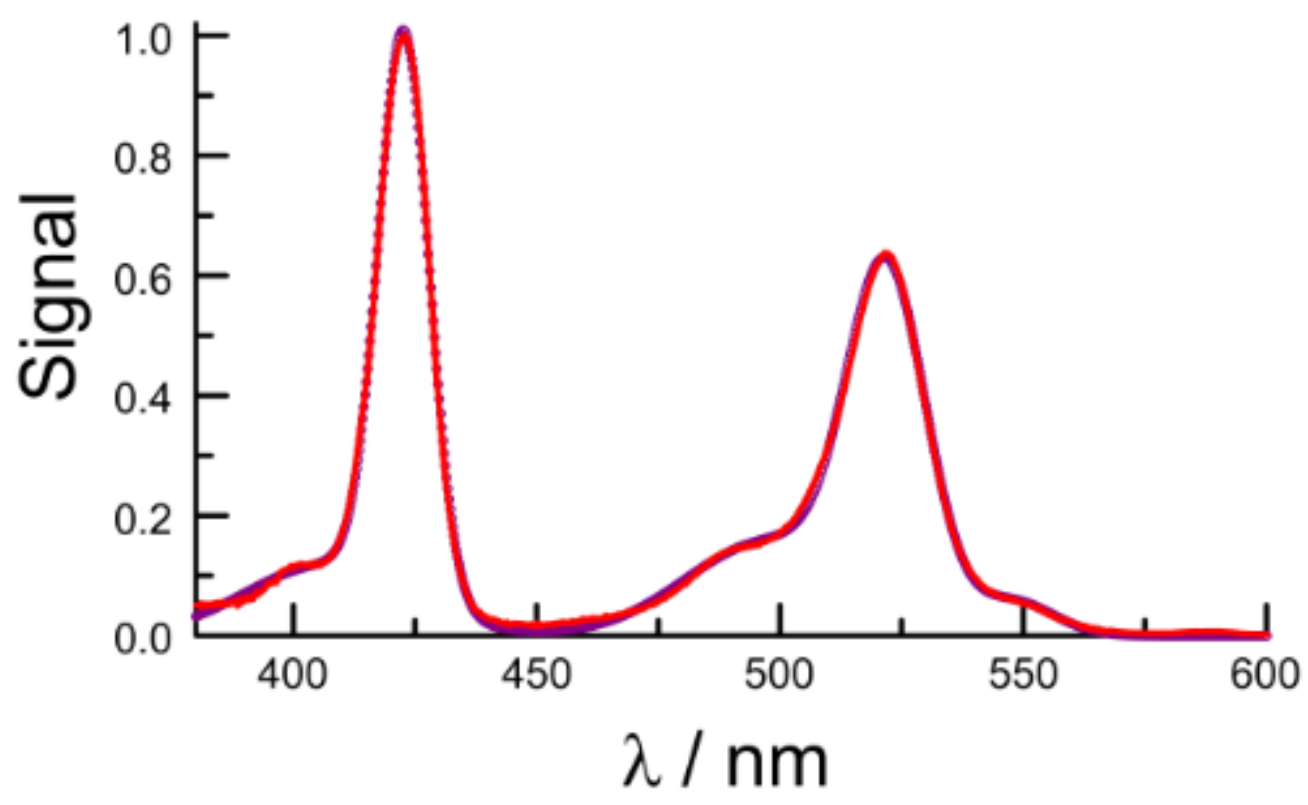

Figure S29. Comparison of normalized absorption (indigo circles) and excitation (red curve) spectra recorded for $\mathrm{ZnPB}_{4}$ by monitoring fluorescence at $690 \mathrm{~nm}$. This emission is associated with the $\mathrm{ZnP}$ unit. The lowest-energy Q-band transition is not seen under these conditions. The excitation spectrum is the average of 20 individual records. Spectra were recorded with the same slit widths and at the same level of resolution. 


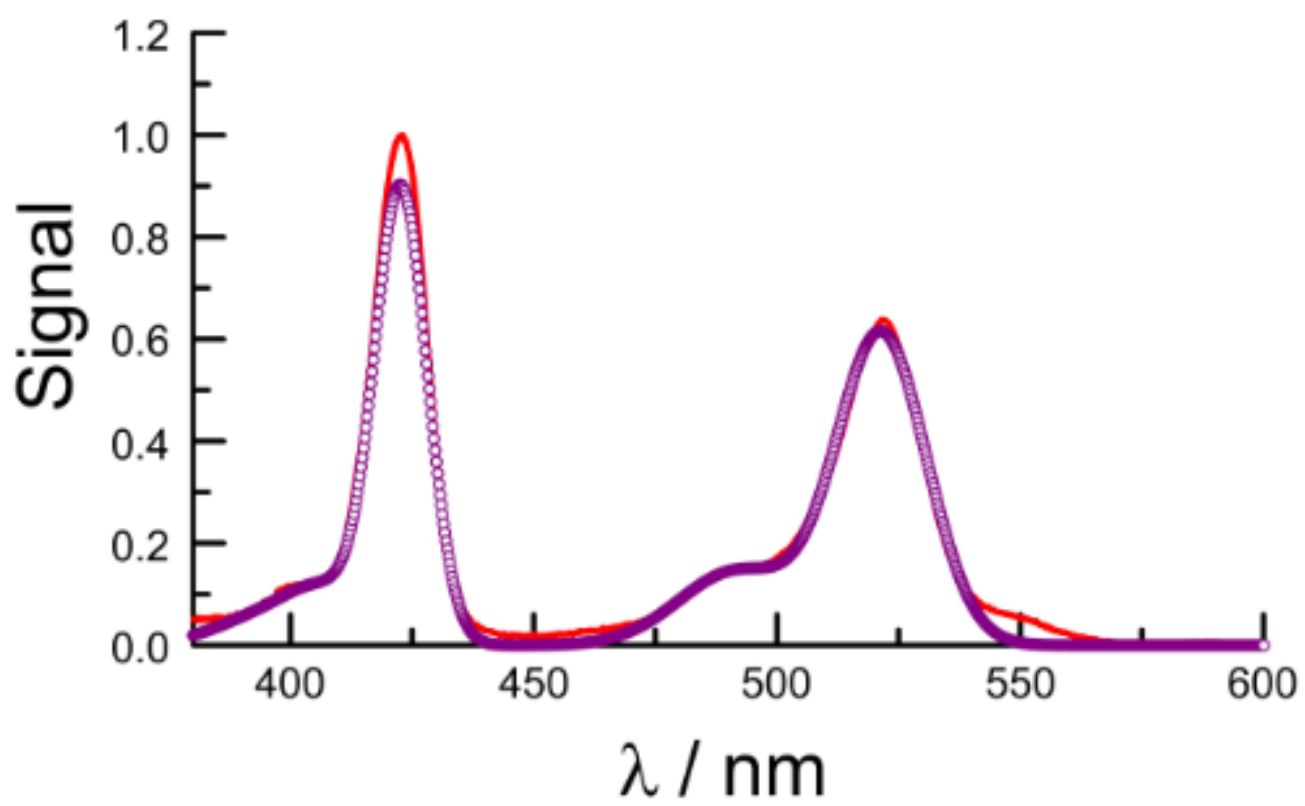

Figure S30. Comparison of normalized absorption (red curve) and excitation (indigo circles) spectra recorded for $\mathrm{ZnPB}_{4}$ by monitoring fluorescence at $560 \mathrm{~nm}$. This emission is associated with the BOD unit. Spectra were normalized at $490 \mathrm{~nm}$. The excitation spectrum is the average of 20 individual records. Spectra were recorded with the same slit widths and at the same level of resolution. 
S7. Triplet-triplet annihilation at high excitation density

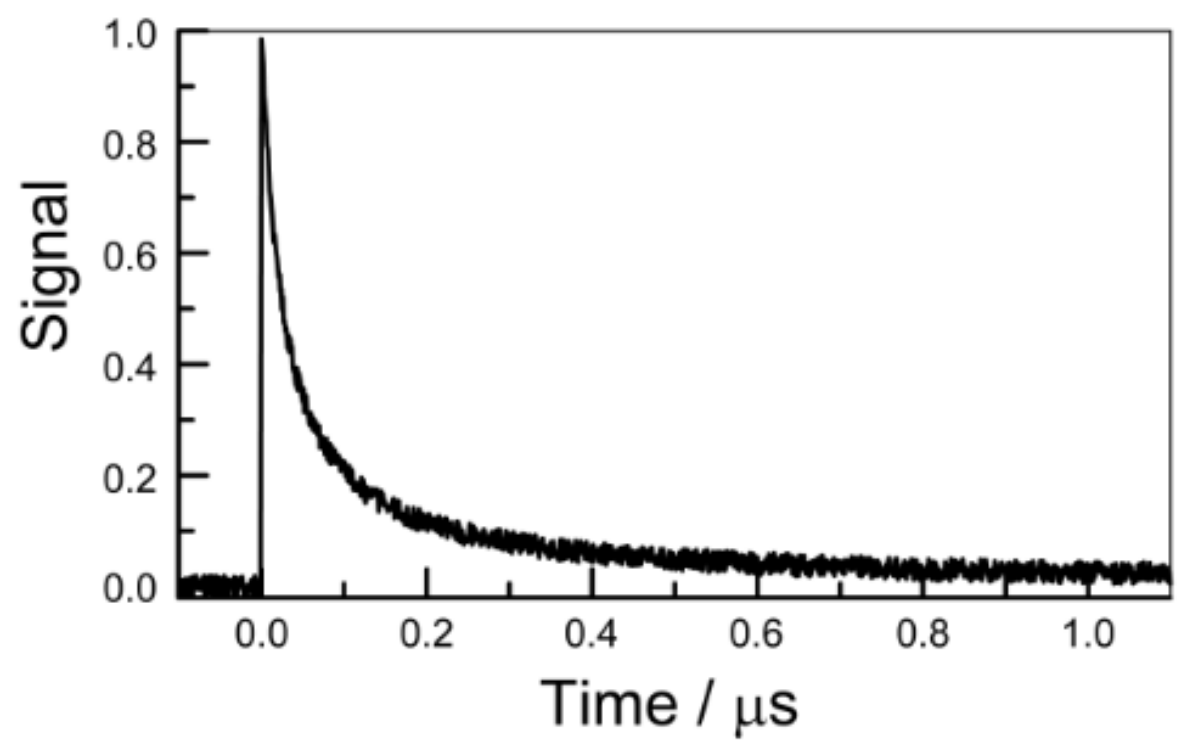

Figure S31. Kinetic trace for decay of the triplet-excited state detected for $\mathrm{FbPB}_{4}$ in de-aerated toluene following excitation at $525 \mathrm{~nm}$ with a 4-ns laser pulse at the maximum (i.e., $40 \mathrm{~mJ} /$ pulse) excitation density. The decay kinetics correspond to mixed first- and second-order processes. The experimental trace was recorded at 440 $\mathrm{nm}$ and can be attributed to the FbP triplet state.

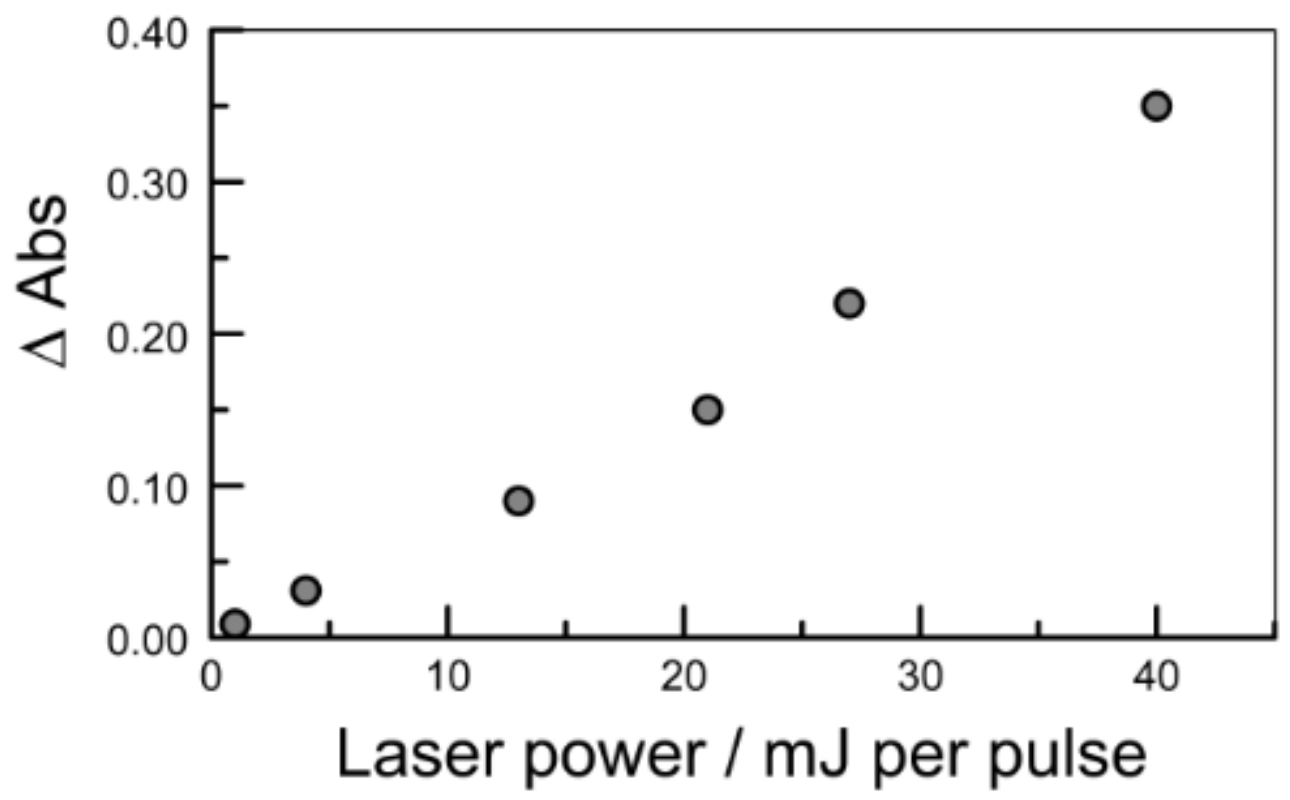

Figure S32. Effect of incident laser intensity on the differential absorbance at $440 \mathrm{~nm}$ as recorded for $\mathrm{FbPB}_{4}(30 \mu \mathrm{M})$ in de-aerated toluene. At the maximum intensity, the conversion of ground state to triplet state is around $50 \%$. 


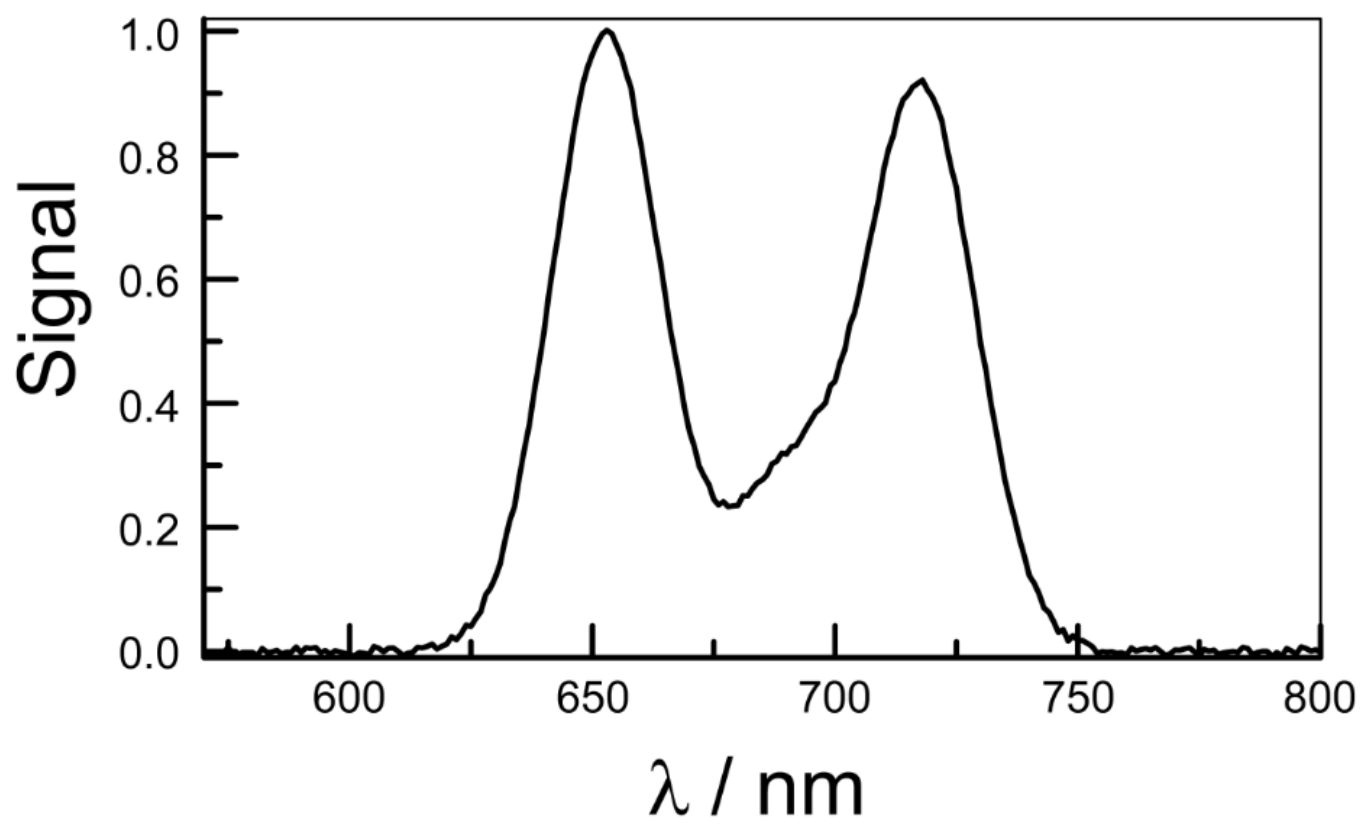

Figure S33. Spectrum recorded $20-25$ ns after excitation of $\mathrm{FbPB}_{4}$ in de-aerated toluene without the pulsed monitoring beam and attributed to delayed fluorescence. Approximately 250 individual spectra were averaged to obtain the final spectrum.

For triplet-triplet annihilation studies made with $\mathrm{FbPB}_{4}$ in de-aerated toluene, the excitation wavelength was $525 \mathrm{~nm}$ and transient absorbance measurements were made at $440 \mathrm{~nm}$. The absorbance of the ground state was ca. 1.6 in a cell with optical path length of $2 \mathrm{~mm}$. Analysis of the signal allows calculation of $\mathrm{k}_{1}$ and $\mathrm{k}_{2}$ where the latter is a pseudo-first-order rate constant defined by Equation $\mathbf{S 1 0}$. The limits for $\mathrm{k}_{1}$ can be obtained from kinetics measurements made a very low laser intensity. In order to obtain the bimolecular rate constant, $\mathrm{kTT}_{\mathrm{T}}$, it is necessary to know the corresponding differential molar absorption coefficient, $\varepsilon$ T, for the triplet state at the monitoring wavelength and the path length, I. This adds an extra degree of uncertainty when comparing different compounds. Analysis of Figure S31 in terms of Equation S11 allows the estimation of the fractional contribution, $\mathrm{f}_{2}$, to the initial absorbance made by the second-order component. In this case, $f_{2}$ corresponds to ca. $43 \%$. The term $D_{0}$ refers to the maximum absorbance value corrected for any fast decay of the triplet state.

$$
k_{2}=\frac{k_{T T}}{\varepsilon_{T} \times l}
$$




$$
f_{2}=\frac{k_{2} D_{0}}{k_{2} D_{0}+k_{1}}
$$

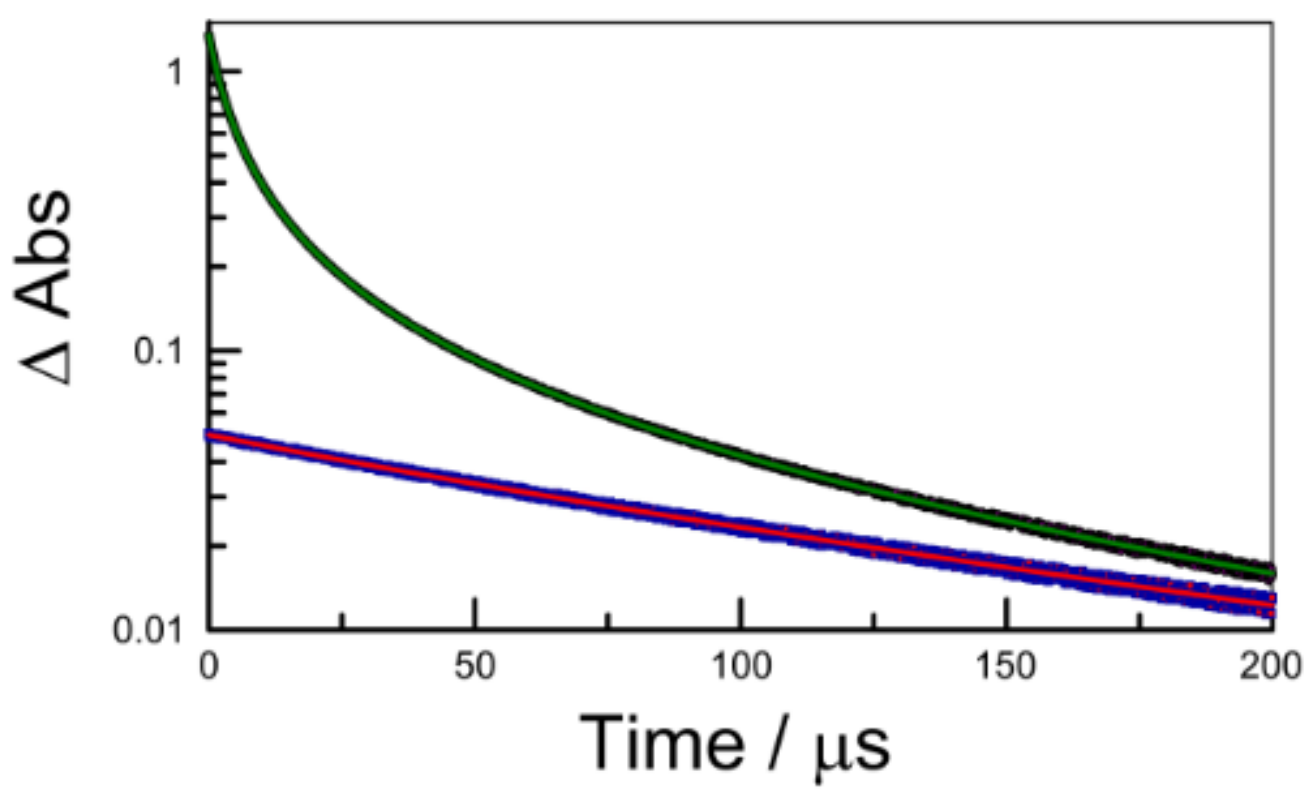

Figure S34. Examples of decay kinetic traces recorded for ZnTPP $(70 \mu \mathrm{M})$ in deaerated toluene at two different laser intensities. Excitation was made at $550 \mathrm{~nm}$. The lower panel (blue curve) corresponds to a relatively low (i.e., $1.5 \mathrm{~mJ} /$ pulse) excitation density, giving a maximum differential absorbance at $470 \mathrm{~nm}$ of 0.055 measured with a path length of $5 \mathrm{~mm}$. The upper trace corresponds to an excitation density of 40 $\mathrm{mJ} /$ pulse and gives a maximum differential absorbance of 1.35 at $470 \mathrm{~nm}$ as measured with a path length of $5 \mathrm{~mm}$. In both cases, the line drawn through the data points refers to a non-linear least-squares fit to Equation 3 with $\mathrm{k}_{1}=5,260 \mathrm{~s}^{-1}$. Analysis of the upper trace allows estimation of $\mathrm{k}_{2}$ as being $6.5 \times 10^{4} \mathrm{~s}^{-1}$ while the conversion of ground state into triplet state is ca. $50 \%$. The $x$-axis is presented in a semi-logarithmic form to emphasize the change in linearity with increased excitation density. 


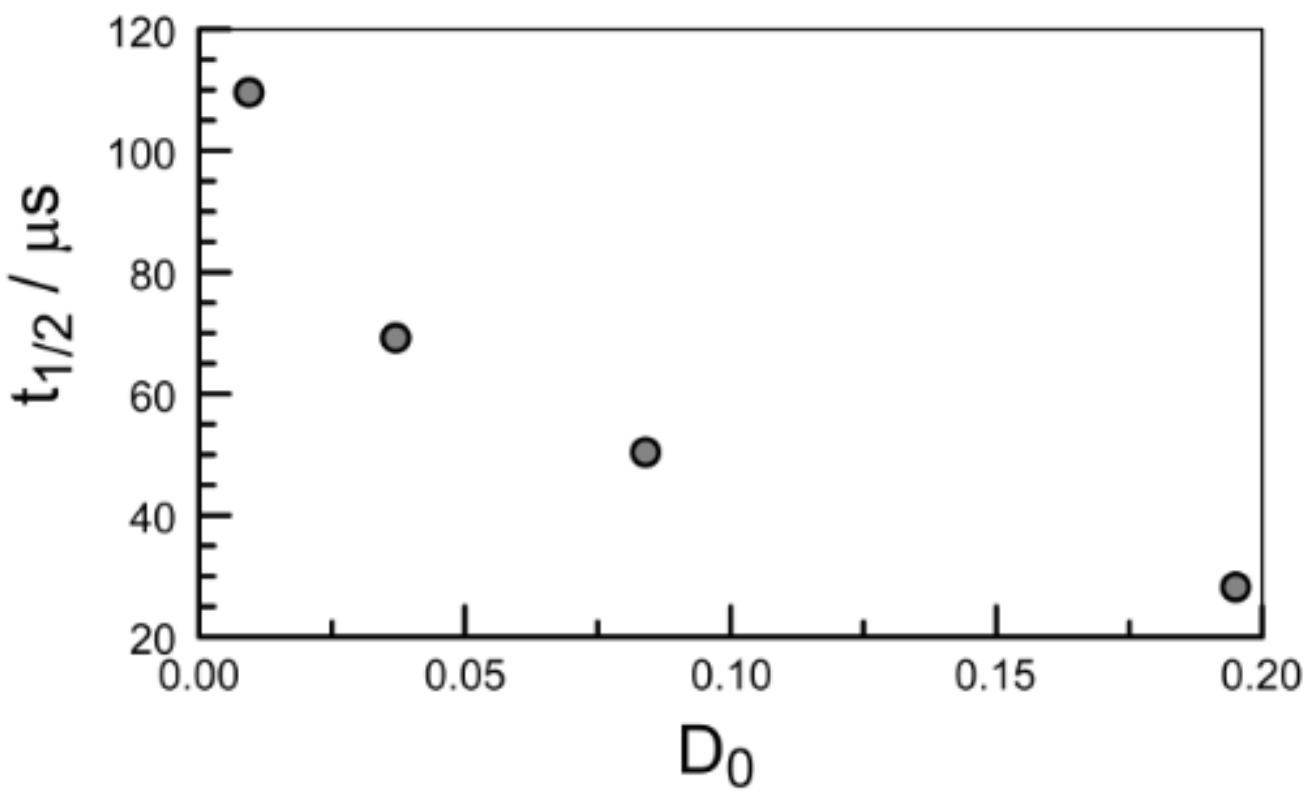

Figure S35. Relationship between the first half-life for the triplet state of $\mathrm{ZnP}$ and the initial absorbance calculated by fitting the decay curve to Equation 3 . The experiment refers to $\mathrm{ZnPB}_{4}(19.4 \mu \mathrm{M})$ in de-aerated toluene. Laser excitation was made at $480 \mathrm{~nm}$ and absorbance was measured at $539 \mathrm{~nm}$ with a path length of $5 \mathrm{~mm}$. The maximum differential absorbance corresponds to ca. $70 \%$ conversion of the ground-state to the triplet state. 


\section{S8. References}

(S1) Sugimoto, H,; Muto, M.; Tanaka, T.; Osuka, A. Synthesis of BODIPYAppended Subporphyrins. Eur. J. Org. Chem. 2011, 1, 71-77.

(S2) Förster, T. Zwischenmolekulare Energiewanderung und Fluoreszenz [Intermolecular energy migration and fluorescence]. Annal. Phys. 1948, 437, 55-75.

(S3) Barigelletti, F.; Flamigni, L.; Collin, J. P.; Sauvage, J. P. Vectorial Transfer of Electronic Energy in Rod-like Ruthenium-Osmium Dinuclear Complexes. Chem. Commun. 1997, 333-338.

(S4) Hedley, G. J.; Ruseckas, A.; Benniston, A. C.; Harriman, A.; Samuel, I. D. W. Ultrafast Electronic Energy Transfer Beyond the Weak Coupling Limit in a Proximal but Orthogonal Molecular Dyad. J. Phys. Chem. A 2015, 119, 12665-12671.

Benniston, A. C.; Harriman, A.; Li, P. Y.; Patel, P. V.; Sams, C. A. A Strategy for the Synthesis of Metal Bis(2,2 ': 6 ',2 "-terpyridine)-Terminated Molecular Dyads Having Controlled Torsion Angles at the Central Biphenyl Linker. J. Org. Chem. 2006, 71, 3481-3493.

(S6) Closs, G. L.; Piotrowiak, P.; Mclnnis, J. M.; Fleming, G. R. Determination of Long-Distance Intramolecular Triplet Energy-Transfer Rates - A Quantitative Comparison with Electron-Transfer. J. Am. Chem. Soc. 1988, 110, 2652-2653.

(S7) Andrews, D. L. A Unified Theory of Radiative and Radiationless Molecular Energy Transfer. Chem. Phys. 1989, 135, 195-201.

(S8) Hablot, D.; Ziessel, R.; Alamiry, M. A. H.; Bahraidah, E.; Harriman, A. Nanomechanical Properties of Molecular-Scale Bridges as Visualised by Intramolecular Electronic Energy Transfer. Chem. Sci. 2013, 4, 444-453.

(S9) Marciniak, H.; Auerhammer, N.; Ricker, S.; Schmiedel, A.; Holzapfel, M.; Lambert, C. Reduction of the Fluorescence Transition Dipole Moment by Excitation Localization in a Vibronically Coupled Squaraine Dimer. J. Phys. Chem. C 2019, 123, 3426-3432.

(S10) Mårtensson, J. Calculation of the Förster Orientation Factor for DonorAcceptor Systems with One Chromophore of Threefold or Higher Symmetry: Zinc Porphyrin. Chem. Phys. Lett. 1994, 229, 449-456. 
(S11) Hurley, J. K.; Sinai, N.; Linschitz, H. Actinometry in Monochromatic Flash Photolysis: The extinction Coefficient of Triplet Benzophenone and Quantum Yield of Triplet Zinc Tetraphenyl Porphyrin. Photochem. Photobiol. 1983, 38, 9-14.

(S12) Karlsson, J. K. G.; Atahan, A.; Harriman, A.; Tojo, S.; Fujitsuka, M.; Majima, T. Pulse Radiolysis of TIPS-Pentacene and a Fluorene-bridged Bis(pentacene): Evidence for Intramolecular Singlet-Exciton Fission. J. Phys. Chem. Lett. 2018, 9, 3934-3938.

(S13) Bensasson, R. V.; Land, E. J. Triplet-Triplet Extinction Coefficients via Energy Transfer. Trans. Faraday Soc., 1971, 67, 1904-1915.

(S14) Quimby, D. J.; Longo, F. R. Luminescence Studies on Several Tetraarylporphins and Their Zinc Derivatives. J. Am. Chem. Soc. 1975, 97, 5111-5117.

(S15) Seybold, P. G.; Gouterman, M. Porphyrins: XIII: Fluorescence Spectra and Quantum Yields. J. Mol. Spectrosc. 1969, 31, 1-13.

(S16) Pekkarinen, L.; Linschitz, H. Studies on Metastable States of Porphyrins. II. Spectra and Decay Kinetics of Tetraphenylporphine, Zinc Tetraphenylporphine and Bacteriochlorophyll. J. Am. Chem. Soc. 1960, 82, 2407-2411.

(S17) Al-Sharif, H. H. T.; Ziessel, R.; Waddell, P. G.; Dixon, C.; Harriman, A. Origin of Fluorescence from Boranils in the Crystalline Phase. J. Phys. Chem. A 2020, 124, 2160-2172. 